\title{
Treatment-resistant depression: therapeutic trends, challenges, and future directions
}

\author{
This article was published in the following Dove Press journal: \\ Patient Preference and Adherence \\ 30 April 2012 \\ Number of times this article has been viewed
}

\author{
Khalid Saad Al-Harbi \\ Medical College, King Saud Bin \\ Abdulaziz University for Health \\ Sciences, King Abdulaziz Medical City, \\ Riyadh, Kingdom of Saudi Arabia
}

Background: Patients with major depression respond to antidepressant treatment, but $10 \%-30 \%$ of them do not improve or show a partial response coupled with functional impairment, poor quality of life, suicide ideation and attempts, self-injurious behavior, and a high relapse rate. The aim of this paper is to review the therapeutic options for treating resistant major depressive disorder, as well as evaluating further therapeutic options.

Methods: In addition to Google Scholar and Quertle searches, a PubMed search using key words was conducted, and relevant articles published in English peer-reviewed journals (1990-2011) were retrieved. Only those papers that directly addressed treatment options for treatment-resistant depression were retained for extensive review.

Results: Treatment-resistant depression, a complex clinical problem caused by multiple risk factors, is targeted by integrated therapeutic strategies, which include optimization of medications, a combination of antidepressants, switching of antidepressants, and augmentation with non-antidepressants, psychosocial and cultural therapies, and somatic therapies including electroconvulsive therapy, repetitive transcranial magnetic stimulation, magnetic seizure therapy, deep brain stimulation, transcranial direct current stimulation, and vagus nerve stimulation. As a corollary, more than a third of patients with treatment-resistant depression tend to achieve remission and the rest continue to suffer from residual symptoms. The latter group of patients needs further study to identify the most effective therapeutic modalities. Newer biomarker-based antidepressants and other drugs, together with non-drug strategies, are on the horizon to address further the multiple complex issues of treatment-resistant depression.

Conclusion: Treatment-resistant depression continues to challenge mental health care providers, and further relevant research involving newer drugs is warranted to improve the quality of life of patients with the disorder.

Keywords: treatment-resistant depression, antidepressants, biomarkers, therapeutic options, somatic therapies

\section{Introduction}

Major depression is a common debilitating disorder affecting $10 \%-15 \%$ of the population per year. Despite advances in the understanding of the psychopharmacology and biomarkers of major depression and the introduction of several novel classes of antidepressants, only $60 \%-70 \%$ of patients with depression respond to antidepressant therapy. Of those who do not respond, 10\%-30\% exhibit treatment-resistant symptoms coupled with difficulties in social and occupational function, decline of physical health, suicidal thoughts, and increased health care utilization. Treatment-resistant depression represents a dilemma for health care providers. Major depression with a poor or unsatisfactory response to two adequate (optimal dosage and duration) trials of two
Correspondence: Khalid Saad Al-Harb Medical College, King Saud Bin Abdulaziz University for Health Sciences, King Abdulaziz Medical City, Riyadh, Kingdom of Saudi Arabia Tel +966 I2520088

Email ks-alharbi@hotmail.com 
different classes of antidepressants has been proposed as an operational definition of treatment-resistant depression. ${ }^{1-4}$

It is reported that at any one time 14 million people suffer from depression, and only $50 \%$ of them receive some form of treatment. Up to $70 \%$ of people who have depression show substantial improvement as measured by commonly used rating scales, such as the Hamilton Rating Scale for Depression (HRSD), ${ }^{5,6}$ but they require additional psychosocial interventions for achieving complete remission. It is estimated that $10 \%-30 \%$ of patients with major depression do not respond to typical antidepressant medications, ${ }^{7}$ and this group of patients needs trials of a variety of treatment strategies. For this purpose, it is particularly important to determine the adequacy and outcome of prior treatment trials by using the Antidepressant Treatment History Form that helps to exclude "pseudoresistance" cases. ${ }^{8}$ Complete remission is achieved in 70\%-90\% of patients with depression, leaving $10 \%-30 \%$ refractory to treatment, and managed by a variety of therapeutic modalities. Unfortunately, approximately $30 \%$ of patients with treatment-resistant depression do not respond to any treatment. ${ }^{9,10}$

According to the findings from the Sequenced Treatment Alternatives to Relieve Depression (STAR*D) study, $50 \%-66 \%$ of patients with depression do not recover fully on an antidepressant medication and one-third of patients do have a remission of their depressive symptoms. ${ }^{11,12}$ It is obvious that use of a variety of treatment approaches versus only an antidepressant makes the outcome variable in patients with major depression. Notably, the results of mega STAR*D studies open windows into the effectiveness or ineffectiveness of antidepressant medications among patients seeking treatment in real-world settings, including in primary health care ${ }^{13,14}$ and help clinicians to make treatment decisions in patients with treatment-resistant depression. The prevalence of both treatment-resistant depression and non-treatment-resistant depression would impressively be variable across time attributed to methodological issues, definition of treatment-resistant depression, and the therapeutic options used, including neurostimulation therapies.

Treatment-resistant depression defies true definition ${ }^{9}$ (Table 1), but mental health experts agree that it should only be diagnosed in patients who have not been helped by two or more antidepressant treatment trials of adequate dose and duration. To add difficulty to the definition of treatment-resistant depression, treatment response and success has different meanings across multiple research settings. By and large, treatment-resistant depression evades universal definition and meaning, and poses a number of diagnostic
Table I Suggested terminology for treatment-resistant depression?

\begin{tabular}{ll}
\hline $\begin{array}{l}\text { Treatment } \\
\text { non-response }\end{array}$ & $\begin{array}{l}\text { A response that is poor enough with significant } \\
\text { residual symptoms that a change in the treatment } \\
\text { plan is called for (eg, failure to evidence at least a }\end{array}$ \\
$50 \%$ reduction in the HRSD score
\end{tabular}

Abbreviation: HRSD, Hamilton Rating Scale for Depression.

and therapeutic challenges to mental health experts. The aim of this paper is to review the therapeutic options for treating resistant major depressive disorder, as well as evaluating further therapeutic interventions.

\section{Search methods}

In addition to Google Scholar and Quertle websites, literature searches were also conducted using PubMed for the years 1990-2011 and entering the keywords "treatment-resistant depression", "treatment-refractory depression", "partial response depression", and "nonresponsive depression". These words were combined with tricyclic antidepressants (TCA), selective serotonin reuptake inhibitors (SSRI), serotonin norepinephrine reuptake inhibitors (SNRI), and atypical antipsychotics, somatic therapies, such as electroconvulsive therapy (ECT), vagus nerve stimulation (VNS), deep brain stimulation (DBS), repetitive transcranial magnetic stimulation (rTMS), magnetic seizure therapy, transcranial direct current stimulation (tDCS), and psychotherapy for a second round of computer searching. 
Another round of searching included a combination of keywords, ie, "treatment-resistant depression with augmentation strategies", "combined antidepressants", "switching approaches", "names of individual antidepressant medications", and "nonpharmacological interventions". As a corollary, relevant articles published in English peer-reviewed journals were retrieved. Only those papers including original studies, clinical trials, systematic reviews, and meta-analyses, which directly addressed treatment-resistant depression, were retained for extensive review and inclusion in this study. Some exceptions were made with regard to small case series, and related mainly to somatic therapies.

\section{Therapeutic trials: pros and cons}

Well designed clinical trials provide strong evidence-based data for antidepressant therapy for treatment-resistant depression, but there are many difficulties in interpreting their results. There is no absolutely correct dosage for a specific antidepressant, because dosage requirements vary with age, gender, weight, physical health, concomitant medication usage, and tolerance. Confirmation of treatment adequacy by serial plasma drug levels is not the rule in clinical practice, and valid plasma level-response relationships are limited to only a subgroup of TCA and lithium, ${ }^{9}$ and are now extended to certain newer antidepressants. In a study that examined the relationship between plasma antidepressant concentration and both clinical response and adverse effects in treatment-resistant depressed adolescents, 334 participants with major depression who had not responded to an SSRI were randomized to one of four treatments, ie, switch to another SSRI (fluoxetine, citalopram, or paroxetine), switch to venlafaxine, switch to SSRI + cognitive behavior therapy, or switch to venlafaxine + cognitive behavior therapy. Adolescents who did not improve by 6 weeks had their dose increased. Plasma concentrations of medication and metabolites were measured at 6 weeks in 244 participants and at 12 weeks in 204 participants.

Adolescents treated with citalopram whose plasma concentration was equal to or greater than the geometric mean showed a higher response rate compared with those having less than the geometric mean, with parallel but nonsignificant findings for fluoxetine. A dose increase of citalopram or fluoxetine at week 6 was most likely to result in a response when it led to a change in concentration from less than the geometric mean at 6 weeks to the geometric mean or greater at week 12 . Plasma levels of paroxetine, venlafaxine, or O-desmethylvenlafaxine were not related to clinical response. Exposure was associated with more cardiovascular and dermatologic side effects in those receiving venlafaxine. It was concluded that the antidepressant concentration may be useful in optimizing treatment for depressed adolescents receiving fluoxetine or citalopram. ${ }^{15}$ With respect to psychotherapy, adequacy of treatment may depend on the number of sessions, the expertise of the practitioner, the therapist's adherence to a particular form of therapy, and also interaction within the patienttherapist dyad. The efficacy of ECT trials may be gauged by the total number of treatments, the use of bilateral electrode placement, and verification of seizure occurrence and its timing by electroencephalographic monitoring. Therefore, treatment resistance is linked to a certainty about the adequacy of a specific treatment trial. ${ }^{16-19}$

Researchers have categorized treatment-resistant depression in accordance with antidepressant trials as: stage 0 , has not had a single adequate trial of medication; stage 1, failure of an adequate trial of one class of an antidepressant, ie, monotherapy; stage 2, failure of adequate trials of two distinctly different classes, ie, an SSRI and TCA, as two monotherapy trials; stage 3 , stage 2 plus failure to respond to one augmentation strategy, ie, lithium or thyroid augmentation of one of the monotherapies; stage 4, stage 3 plus a failure on a second augmentation strategy in terms of monoamine oxidase inhibitors; and stage 5 , stage 4 plus failure of an adequate course of ECT. ${ }^{9}$ There are other staging methods for treatment-resistant depression, including the Antidepressant Treatment History Form, the Thase and Rush model, the European Staging model, the Massachusetts General Hospital Staging model, and the Maudsley Staging model, with variable predictive validity and reliability. ${ }^{20}$ These staging methods help researchers and clinicians to understand the severity and chronicity of treatment-resistant depression and plan trial interventions accordingly.

\section{Patient concerns}

Treatment-resistant depression is a difficult condition to treat. Patients with the disorder should interactively share their inner experiences with the treating expert and be able to ask freely any questions related to risk factors underlying treatment-resistant depression, better treatment options, lifestyle changes, costs and insurance coverage, a proper medication schedule, duration of treatment, severity of side effect, suicidal thoughts and attempts, non-suicidal selfinjurious behaviors, and intolerance issues. Other related issues to be discussed with patients having treatmentresistant depression are adherence to treatment, impact of medical comorbidities such as heart disease, cancer, thyroid disease, anemia, and eating disorders, interactions 
between antidepressants and other medications including herbal supplements, manifestations of impending relapse, and genetic vulnerability. Mental health experts should also address in nontechnical language patients' concerns about somatic therapies, including ECT, VNS, tDCS, rTMS, magnetic seizure therapy, and DBS. ${ }^{12,19}$

Patients with treatment-resistant depression should know about the predictors of good and bad outcomes of treatment. In a UK study that aimed to assess the impact of post-treatment clinical states on longer-term outcome recruited 118 patients with treatment-resistant depression who received specialist inpatient treatment and were followed up for a median of 3 years. Longitudinal outcome, dichotomized into good and poor, was used as the primary outcome and functional measures were used as secondary outcomes. Among the 118 treated patients, 40 (34\%) entered clinical remission, 36 (31\%) entered partial remission, and 42 (37\%) remained in a depressive episode at discharge. At follow-up, $35 \%$ had a longitudinally defined poor outcome. According to this study, post-treatment clinical status was the main predictor of both poor and good outcome. Nearly $50 \%$ of patients achieved post-discharge recovery, and subsequently had a longer-term outcome comparable with that of patients discharged in remission. Patients who remained in an episode post-treatment were more symptomatically and functionally impaired. In summary, post-treatment clinical states are a useful guide for clinicians in projecting the longer-term outcome for patients with treatment-resistant depression. The persistence of residual or syndromal symptoms predicts a poorer longer-term outcome, whereas treatment to remission is associated with better outcomes. ${ }^{21}$

In another study of young adolescents with SSRI-resistant depression, suicide attempts and nonsuicidal self-injuries were found to have clinical and prognostic significance. This research further called for preventive and therapeutic strategies for treatment-resistant depression and its associated adverse behavioral complications. ${ }^{22}$ Patients with treatmentresistant depression also need to be familiar with issues related to weight gain. ${ }^{23}$ Like patients with depression and general medical conditions, ${ }^{24}$ patients with treatment-resistant depression also have cost concerns associated with variable outcomes and poor adherence to treatment or combined therapies. Patients with depression who respond/remit on antidepressant treatment bear less cost than those who have persistent depression. ${ }^{25,26}$ By and large, treatment-resistant depression is associated with extensive use of depressionspecific and general medical services, which poses a substantial economic burden, together with work loss costs. ${ }^{27,28}$
In a related context, a randomized, controlled trial evaluated the incremental cost-effectiveness over 24 weeks of combined cognitive behavior therapy plus a switch to a different antidepressant medication versus a medication switch only in adolescents who continued to have depression despite adequate initial treatment with an SSRI. Participants were randomly assigned to switch to a different medication only or to switch to a different medication plus cognitive behavior therapy. Clinical outcomes were depression-free days, depression-improvement days, and quality-adjusted life-years based on depression-free days. It was revealed that combined treatment had a higher net benefit for subgroups of youth without a history of substance abuse, with lower levels of hopelessness, and with comorbid conditions. For youth with SSRI-resistant depression, combined treatment decreases the number of days with depression and was more costly. It was concluded that, depending on a decision-maker's willingness to pay, combined therapy may be cost-effective, particularly for some subgroups. ${ }^{29}$

\section{Risk factors}

There is no one reason for treatment-resistant depression. Depression is a heterogeneous disorder, as reflected by treatment heterogeneity and variable nonresponse rates, ${ }^{30}$ and the latter could be due to patient age and gender. Elderly patients may be somewhat less treatment-responsive than those at midlife. Conversely, younger women may benefit less from TCA than men or women treated with monoamine oxidase inhibitors. ${ }^{9}$ Individuals with fewer interpersonal or economic resources, minority status, lower function and quality of life, and chronic depression may also be less responsive to antidepressant treatment. Furthermore, a higher level of objective stress, poorer social support and family networks, and/or a greater risk of noncompliance also contribute to treatment-resistant depression. ${ }^{9,31,32}$ However, for most patients with treatment-resistant depression, it is probably a combination of different risk factors (Table 2) which are as follows: not staying on prescribed antidepressants long enough, ie, for 6-12 weeks when they have their full effect; skipping doses, in terms of poor adherence (blood sample analysis for measuring drug levels is an option for confirming or excluding such a possibility); unpleasant side effects of prescribed psychiatric and non-psychiatric drugs; drug-drug interactions in particular antidepressants and medical treatments; the wrong medicine or the wrong dose for the individual in question; genetic disposition in terms of fast or slow metabolizers of antidepressants; medical comorbid conditions, such as hypothyroidism and anemia, which also 
Table 2 Risk factors for treatment-resistant depression

\begin{tabular}{|c|c|}
\hline Risk factors & Remarks \\
\hline $\begin{array}{l}\text { Not staying on a } \\
\text { medicine long enough }\end{array}$ & $\begin{array}{l}\text { Antidepressants can take as long as } 6-8 \\
\text { weeks before they fully take effect }\end{array}$ \\
\hline Skipping doses & $\begin{array}{l}\text { Take depression medicine exactly as } \\
\text { prescribed to know it is working effectively }\end{array}$ \\
\hline Unpleasant side effects & $\begin{array}{l}\text { Consult doctor for emerging side effects of } \\
\text { antidepressants because he/she may offer } \\
\text { some help including informing that side } \\
\text { effects tend to decrease over time }\end{array}$ \\
\hline Drug interactions & $\begin{array}{l}\text { Some medicines do not work well } \\
\text { with antidepressants and in some cases } \\
\text { interactions with dangerous consequences } \\
\text { may occur }\end{array}$ \\
\hline $\begin{array}{l}\text { Wrong medicine } \\
\text { or wrong dose }\end{array}$ & $\begin{array}{l}\text { Antidepressant drugs work very differently } \\
\text { in different people and finding the right } \\
\text { medicine, at the right dose, takes trial } \\
\text { and error }\end{array}$ \\
\hline Genes & $\begin{array}{l}\text { Researchers have found a gene that } \\
\text { interferes in the synthesis of tryptophan, } \\
\text { a substrate for serotonin synthesis, } \\
\text { deficiency of which contributes to } \\
\text { treatment resistance }\end{array}$ \\
\hline $\begin{array}{l}\text { Co-occurring medical } \\
\text { conditions }\end{array}$ & $\begin{array}{l}\text { Medical conditions like heart disease, } \\
\text { cancer, or thyroid problems, and eating } \\
\text { disorders can contribute to depression, } \\
\text { and need to be treated simultaneously }\end{array}$ \\
\hline $\begin{array}{l}\text { Co-occurring psychiatric } \\
\text { conditions }\end{array}$ & $\begin{array}{l}\text { Co-occurring Axis I and Axis II diagnosis } \\
\text { needs concurrent treatment }\end{array}$ \\
\hline Alcohol or drug abuse & $\begin{array}{l}\text { Depression may pre- or post-cede } \\
\text { substance abuse that need proper } \\
\text { treatment as well }\end{array}$ \\
\hline Wrong diagnosis & $\begin{array}{l}\text { Some people are simply misdiagnosed with } \\
\text { treatment-resistant depression and need } \\
\text { comprehensive reassessment }\end{array}$ \\
\hline $\begin{array}{l}\text { Poverty and low } \\
\text { education }\end{array}$ & $\begin{array}{l}\text { As environmental effect sizes in affected } \\
\text { individuals with treatment-resistant } \\
\text { depression may negatively interfere with } \\
\text { compliance }\end{array}$ \\
\hline
\end{tabular}

contribute to depression by several mechanisms and each needs a separate treatment approach, and ignoring either of them would result in treatment failure and nihilism; and eating disorders, alcohol, and other substance-use disorders, which tend to worsen the depression or might be the main underlying cause of depression. ${ }^{9,32}$ Furthermore, breakthrough episodes can also occur among patients partially or fully improved that may contribute to the resistant nature of depression. ${ }^{33}$ In addition, misdiagnosis of depression also leads to treatment-resistant depression. ${ }^{34}$ Misdiagnosis also includes failure to identify the actual subtype of depression, such as atypical, psychotic, bipolar, or melancholic depression, that has an impact on treatment selection and outcome and may require concurrent pharmacotherapy, such as an antipsychotic or augmentation psychotherapy. ${ }^{9}$
Some evidence also indicates a poorer response to TCA in atypical depression, bipolar depression, psychotic depression, and depression associated with significant Axis I, Axis II, or Axis III comorbidity. ${ }^{31}$ Further, major depressive disorder that remains unrecognized and untreated may become treatmentresistant depression. ${ }^{35}$

Another symptomatic correlate of treatment resistance is the global severity of depression. A naturalistic study revealed that most patients with a substantial degree of treatment resistance continue to have significant symptoms and functional disability when receiving their usual treatment. ${ }^{36}$ Finally, the adverse effects of medication and poor compliance determined by poverty and low education may be additional obstacles to successful treatment of depression. ${ }^{19,37,38}$ According to the World Health Organization International Classification of Functioning, Disability and Health, that includes psychiatric disorders, ${ }^{39}$ including major depression and treatment-resistant depression, the participation level of patients with depression is an important treatment component that may influence their outcomes and correspondingly might contribute to treatmentresistant depression. Interestingly, based on the perceived relative therapeutic efficacy of available treatment options, depression may also be seen as a secondary compliance risk factor for treatment-resistant depression. In a recent review, risk factors for treatment-resistant depression in adolescents were identified to be the severity of depression, level of hopelessness and suicidal ideation, psychiatric and medical comorbidities, environmental factors such as family conflict, maternal depression, and history of physical and sexual abuse, as well as pharmacokinetics and other biomarkers..$^{40,41}$

In another study, a team of researchers reported that genetic polymorphisms in the transcription factor, cyclic adenosine monophosphate response element binding (CREB1), could be associated with treatment resistance in patients with depression. ${ }^{42}$ Also, based on an experimental animal study ${ }^{43}$ researchers reported discovering a mutant gene on chromosome 12 that codes for tryptophan hydroxylase-2. This enzyme helps in the biosynthesis of serotonin, and is produced $80 \%$ less than normal by individuals with major or treatment-resistant depression who have this mutant gene, which was also identified in normal individuals (3/219), but much less often than in patients with severe depression $(9 / 87) .{ }^{44}$ The implication of this study is that genetic testing, if developed, could identify patients with depression who would or would not respond satisfactorily to one of the antidepressants, eg, a TCA, SSRI, or SNRI. 
In summary, depressive illness-related factors, personal characteristics, medication variables, and psychosocial stresses collectively contribute to the development of treatment-resistant depression, and are associated with a considerable disease burden. ${ }^{45}$

\section{Therapeutic options}

There are five main strategies (Table 3 ) used to overcome a partial response or lack of response to antidepressant therapy, ie, optimization, switching, combination, augmentation, and somatic therapies. ${ }^{46}$ Because there is no standard treatment approach, mental health experts offer the aforesaid strategies

Table 3 Management strategies for treatment-resistant depression

Therapeutic strategies Remarks
and options

and options

Optimization Maximize dose for adequate time

of antidepressants and check serum levels of prescribed antidepressant if supported by evidencebased data

Switching

of antidepressants

Changing from one ineffective

antidepressant to similar or different class of antidepressant; SSRI/SNRI to TCA, MAOI, and atypical antipsychotics with antidepressant properties

Combination of antidepressants

Adding another antidepressant from different classes, eg, TCA + MAOI,

SSRI + TCA, SSRI + atypical antidepressant, SSRI + buspirone, etc
Augmentation strategies

Somatic therapies Integrated approach

Adjunctive approach

Neurosurgical interventions Continuing research

Adding a second agent that is not an antidepressant but may enhance the antidepressant effect of the drug in question, eg, lithium, thyroid hormones, pindolol, psychostimulants, atypical antipsychotics, sex hormones, anticonvulsants/mood stabilizers, and dopamine agonists

ECT, VNS, rTMS, MST, DBS, and TDCS Use of antidepressants together with other modes of treatment, which include psychotherapy, risk management strategies, CAM therapies, and life style changes such as exercise and school vacation

Use of a treatment to manage the side effects of antidepressants and also to increase its efficacy

Isolated, severe cases of treatmentresistant depression

In genetic, biomarkers, and animal models for drug development

Abbreviations: CAM, complementary and alternative medicine; TDCS, transcranial direct current stimulation; ECT, electroconvulsive therapy; VNS, vagus nerve stimulation; rTMS, repetitive transcranial magnetic stimulation, DBS, deep brain stimulation; MST, magnetic seizure therapy; TCA, tricyclic antidepressant; MAOI, monoamine oxidase inhibitors; SSRI, selective serotonin reuptake inhibitor; SNRI, serotonin-norepinephrine reuptake inhibitor. based on re-evaluation of patients with treatment-resistant depression. The patient with depression not responding to antidepressant monotherapy requires a highly individualized treatment plan and, accordingly, some people will respond to a specific treatment, while others do not. Finding the right approach to treat depression can take a lot of effort and time. ${ }^{29,30}$ Therefore, the following principles need to be followed to manage patients with treatment-resistant depression: ensure accurate diagnosis, including subtype of depression; assess comorbid psychiatric and medical conditions; evaluate psychosocial stressors, as well as social and family support; ensure adequate dose and duration of treatment; monitor and treat adverse events; educate the patient regarding depression and antidepressants; ensure compliance; and aim for remission. The five approaches are now described briefly.

\section{Optimization of antidepressants}

The two core features of this strategy are to optimize dosage and duration of antidepressant therapy for patients who have experienced only partial improvement. The advantages of this strategy are to capitalize on the natural history of episodic depression which remits over time and to counteract the tendency of some patients to discontinue the antidepressant prematurely. Furthermore, it helps to distinguish a true enduring antidepressant response from a more transient placebo response. Specifically, placebo responders have a greater likelihood of relapse between weeks 6 and 12 than patients who have responded to active antidepressants. ${ }^{9,32}$ An adequate trial of antidepressant therapy has been defined by some clinicians as a minimum of 6 weeks. ${ }^{7}$ If the patient exhibits a partial response during this initial period, another 4-6 weeks of treatment should be added. Thus, a total of 10-12 weeks may be required in some cases to elicit a full response to antidepressant therapy. ${ }^{47}$ Irrational prescribing of antidepressant medications with regard to dosage and duration is a common cause of treatment failure ${ }^{9,47}$ and is common in clinical practice. In a study conducted in a managed care environment, only $11 \%$ of patients requiring antidepressant therapy received either an adequate dosage or duration of therapy. ${ }^{48}$ This irrational prescribing trend is particularly common in elderly patients, ${ }^{49}$ and is especially problematic in low-income and middle-income countries. The older literature suggests that routine prescription of maximal doses of TCA, monoamine oxidase inhibitors, and second-generation antidepressants is associated with a greater likelihood of response than more modest doses in patients with treatment-resistant depression. ${ }^{9}$ Notably, administration 
of higher doses of first-generation and second-generation antidepressants in patients with treatment-resistant depression requires monitoring of blood levels to track the clinical response and to avoid adverse effects.

\section{Switching strategies}

The switching approach mainly involves discontinuing an ineffective antidepressant and starting a new antidepressant from a similar or different class in patients with treatmentresistant depression. Earlier studies found response rates of only $10 \%-30 \%$ for TCA in patients with a past history of lack of response to TCA. ${ }^{9}$ A trial course of nortriptyline guided by plasma levels similarly suggested a $30 \%$ response in patients with a prior history of TCA failure. ${ }^{50}$ Conversely, better response rates of up to $70 \%$ have been reported when patients are switched to an alternative class of antidepressant, including the second-generation heterocyclic antidepressants and SSRI/SNRI coupled with a different mechanism of action. ${ }^{7,30,32,47}$ Thase and Rush reviewed the relevant literature on old trend switching approaches involving several within and across classes of antidepressants in the population with treatment-resistant depression and similar conclusions were drawn, with the recommendation to conduct larger, controlled, double-blind, crossover studies of SSRI/ SNRI-resistant depression using newer antidepressants and TCA. ${ }^{9}$ A number of relatively well designed studies, ${ }^{51-67}$ which focused on switching strategies from SSRI in major depression, have been conducted to address these issues, and are summarized in Table 4. A summary of the findings of these studies is as follows: response rate $26 \%-76 \%$; remission rate $28 \%-87 \%$; a TCA might prove to be a strategy of first choice for patients who do not respond to an SSRI; intolerance to one SSRI does not necessarily mean intolerance to the whole class of SSRI; challenges include collecting controlled data to address the equally important question about the effectiveness of an alternate SSRI when another member of this class is not effective; across-class switch is a good treatment option; in patients unresponsive to SSRI, administration of antidepressants with different mechanisms of action is an effective switching strategy; and switching from an SSRI to a TCA and vice versa in patients who do not respond to a 4-week trial is not associated with an improved response. The last observation runs counter to that predicted by current guidelines. ${ }^{68}$

The advantages of this strategy are improved adherence, reduced medication costs, and fewer drug interactions, ${ }^{69}$ while the disadvantages are that therapeutic gains from original antidepressant are lost, the patient has to wait for the new agent to become effective, and relapse or withdrawal symptoms together with adverse effects may occur during the intervening period. This is particularly true if the half-life of the first agent is quite long, as is the case with fluoxetine (35 days), and another SSRI is started before an adequate washout period has occurred. Other antidepressants that require longer washout periods of up to 14 days are clomipramine, tranylcypromine, moclobemide, bupropion, and phenelzine if switched to another TCA, monoamine oxidase inhibitor, or SSRI. Serotonin syndrome, ${ }^{70}$ reflecting toxic serotonin levels in the central nervous system and characterized by hyperalertness, agitation, confusion, restlessness, myoclonus, hyperreflexia, diaphoresis, shivering, tremor, and, possibly, death, may occasionally develop if the washout period was inadequate when switching from one SSRI antidepressant to another. In summary, the risks of toxicity are greater with higher dosage regimens and an inadequate washout period, although urgent cases may necessitate a shorter switching interval.

\section{Combination of antidepressants}

Combination therapy involves the addition of a second antidepressant agent from a different class to the therapeutic regimen of patients with treatment-resistant depression. ${ }^{30,71}$ The additional antidepressant is used for 12 weeks or even months in optimum doses. ${ }^{9}$ Older antidepressants may be used because they are reported to have good results in treatment-resistant depression coupled with severe, recurrent depression. ${ }^{72-74}$ Various types of combination are reported in the literature, but the most common are TCA + SSRI followed by, eg, venlafaxine + TCA, SSRI + SSRI, and SSRI + venlafaxine. ${ }^{75}$ Venlafaxine + mirtazapine is frequently used in clinical practice, and this combination produces a good response in patients with difficult-to-treat depression, which is attributed to the synergistic action of this combination. In one study of 32 patients with persistent depressive illness, the mirtazapine + venlafaxine combination was given at some point over a 3-year period between 2002 and 2005. Clinical response rates were $44 \%$ at 4 weeks and $50 \%$ at 8 weeks. At 6 -month review, $56 \%$ of the original cohort and $75 \%$ of those still receiving treatment had shown a significant response. In total, 44\% experienced some adverse effects. Five patients discontinued treatment due to sedation $(19 \%)$ and weight gain $(19 \%) .{ }^{76}$ In another study, the venlafaxine + mirtazapine combination was given to 22 patients with major depression who had failed one trial of antidepressant therapy. The mean duration of treatment was approximately 8 weeks, producing a response 
Table 4 Summary of clinical studies of switching from an SSRI in major depression

\begin{tabular}{|c|c|c|c|c|}
\hline Reference & $\begin{array}{l}\text { Initial } \\
\text { treatment }\end{array}$ & $\begin{array}{l}\text { Post-switch } \\
\text { treatment }\end{array}$ & Design & Response rate \\
\hline Thase et $\mathrm{a}^{51}$ & Sertraline & Fluoxetine & $\begin{array}{l}\mathrm{n}=106, \text { open, non-response, } \\
\text { or intolerance }\end{array}$ & $63 \%$ \\
\hline $\begin{array}{l}\text { Brown and } \\
\text { Harrison }\end{array}$ & Fluoxetine & Sertraline & $\begin{array}{l}\mathrm{n}=9 \mathrm{I}, \text { open, primarily } \\
\text { intolerant }\end{array}$ & $76 \%$ \\
\hline Zarate et $\mathrm{a}^{53}$ & Fluoxetine & Sertraline & $\begin{array}{l}n=3 \mathrm{I}, \text { open, non-response } \\
\text { or intolerance }\end{array}$ & $\begin{array}{l}42 \% \text { at discharge, } \\
26 \% \text { at follow-up }\end{array}$ \\
\hline Joffe et al ${ }^{54}$ & $\begin{array}{l}\text { Fluoxetine, } \\
\text { Sertraline, } \\
\text { Paroxetine }\end{array}$ & Second SSRI & $\begin{array}{l}\mathrm{n}=55, \text { open, } \\
\text { non-response only }\end{array}$ & $51 \%$ \\
\hline Peselow et al ${ }^{55}$ & Paroxetine & Imipramine & $\begin{array}{l}\mathrm{n}=15, \text { double-blind, } \\
\text { prospective nonresponse }\end{array}$ & $73 \%$ \\
\hline Thase et $\mathrm{al}^{56}$ & Sertraline & Imipramine & $\begin{array}{l}\mathrm{n}=1 \mathrm{I} 7 \text {, double-blind, } \\
\text { cross-over prospective } \\
\text { non-response }\end{array}$ & $\begin{array}{l}60 \% \text { in the sertraline group and } \\
44 \% \text { in the imipramine group }\end{array}$ \\
\hline Nierenberg et $\mathrm{al}^{57}$ & Various & Venlafaxine & $\begin{array}{l}\mathrm{n}=84, \text { open, non-response } \\
\text { to } 3 \text { prior trials }\end{array}$ & $33 \%$ \\
\hline De Montigny et al ${ }^{58}$ & Various & Venlafaxine & $\begin{array}{l}\mathrm{n}=152 \text {, open, nonresponse } \\
\text { to at least one prior trial }\end{array}$ & $\begin{array}{l}58 \% \text { response } \\
28 \% \text { remission }\end{array}$ \\
\hline Kaplan $^{59}$ & $\begin{array}{l}\text { Fluoxetine, } \\
\text { Sertraline, } \\
\text { Paroxetine }\end{array}$ & Venlafaxine & $\begin{array}{l}\mathrm{n}=73 \text {, open, nonresponse } \\
\text { to one prior SSRI }\end{array}$ & $87 \%$ full remission \\
\hline $\begin{array}{l}\text { Poirer and } \\
\text { Boyer }^{60}\end{array}$ & $\begin{array}{l}\text { Various, two } \\
\text { thirds SSRIs }\end{array}$ & $\begin{array}{l}\text { Venlafaxine or } \\
\text { Paroxetine }\end{array}$ & $\begin{array}{l}\mathrm{n}=172 \text {, double-blind, } \\
\text { randomized, nonresponse to } \\
\text { two prior trials, I prospective }\end{array}$ & $\begin{array}{l}\text { Response } \\
52 \% \text { venlafaxine, } 33 \% \text { paroxetine } \\
\text { Remission } \\
42 \% \text { venlafaxine, } 22 \% \text { paroxetine }\end{array}$ \\
\hline McGrath et a ${ }^{61}$ & Fluoxetine & Bupropion & $\begin{array}{l}\mathrm{n}=18 \text {, open, nonresponse } \\
\text { to prior prospective } \\
\text { fluoxetine trial }\end{array}$ & $28 \%$ response \\
\hline Fava et $a^{62}$ & Various SSRI & Mirtazapine & $\begin{array}{l}\mathrm{n}=69 \text {, open, nonresponse } \\
\text { to prior prospective SSRI trial }\end{array}$ & $48 \%$ response \\
\hline Thase et $\mathrm{al}^{63}$ & Various SSRI & $\begin{array}{l}\text { Mirtazapine or } \\
\text { Sertraline }\end{array}$ & $\begin{array}{l}\mathrm{n}=243 \text {, double-blind, } \\
\text { randomized, nonresponse } \\
\text { to one prior SSRI, not sertraline }\end{array}$ & $\begin{array}{l}\text { At week } 3 \text { and } 4 \text { mirtazapine }>\text { sertraline, } \\
P<0.05 \text { ( }>50 \% \text { improvement) and at } \\
\text { week } 8 \text { mirtazapine and sertraline, } P=\text { NS. } \\
\text { Remission rate } 37 \% \text { mirtazapine } \\
\text { and } 29 \% \text { sertraline }\end{array}$ \\
\hline Rapaport et a ${ }^{64}$ & $\begin{array}{l}\text { SSRI, } \\
\text { Citalopram }\end{array}$ & Risperidone & $\begin{array}{l}\mathrm{n}=489, \text { multiple designs, } \\
\text { double-blind, placebo-controlled, } \\
\text { nonresponse to I-3 SSRI failures }\end{array}$ & $\begin{array}{l}\text { Median time to relapse was } 97 \text { days } \\
\text { with risperidone augmentation and } \\
56 \text { with placebo }(P=0.05) \text {; relapse } \\
\text { rates were } 56 \% \text { and } 64 \% \text {, respectively } \\
(P<0.05)\end{array}$ \\
\hline $\begin{array}{l}\text { Lenox-Smith } \\
\text { and Jiang }\end{array}$ & SSRI & $\begin{array}{l}\text { Venlafaxine } \\
\text { Citalopram }\end{array}$ & $\begin{array}{l}\mathrm{n}=406,12 \text {-week, double-blind, } \\
\text { randomized, parallel-group, } \\
\text { multicenter study }\end{array}$ & $\begin{array}{l}\text { Venlafaxine and citalopram with similar } \\
\text { efficacy. In severely depressed patients, } \\
\text { venlafaxine ER was significantly more } \\
\text { effective }\end{array}$ \\
\hline Souery et a ${ }^{66}$ & $\begin{array}{l}\text { Citalopram } \\
\text { Despiramine }\end{array}$ & $\begin{array}{l}\text { Despiramine/ } \\
\text { citalopram }\end{array}$ & $\begin{array}{l}\mathrm{n}=189, \text { nonresponse, } \\
\text { prospective study, } 8 \text { weeks }\end{array}$ & $\begin{array}{l}\text { First } 4 \text { weeks, no difference between } \\
\text { citalopram and despiramine or switch, } \\
\text { but in the next } 4 \text { week, remitter } \\
\text { rates }>\text { among non-switched patients, } \\
\text { switched patients had more score on } \\
\text { HRSD and MADRS, CGI scales }\end{array}$ \\
\hline Rosso et al ${ }^{67}$ & SSRI & $\begin{array}{l}\text { Duloxetine and } \\
\text { bupropion }\end{array}$ & $\begin{array}{l}\mathrm{n}=49, \text { a randomized, } \\
\text { comparison study, } \\
2 \text { SSRI trial failures }\end{array}$ & $\begin{array}{l}\text { Response rate } 60 \%-70 \% \text { and remission } \\
\text { rate } 30 \%-40 \%\end{array}$ \\
\hline
\end{tabular}

Copyright ( ) 2003, Physicians Postgraduate Press. Adapted with permission from Nelson JC. Managing treatment-resistant major depression. J Clin Psychiatry. 2003;64 Suppl 1:5-12.69 Abbreviations: ER, extended-release; HRSD, Hamilton Rating Scale for Depression; MADRS, Montgomery-Åsberg Depression Rating Scale; CGI, Clinical Global Impression; NS, not statistically significant; SSRI, selective serotonin reuptake inhibitors. 
rate of $81.8 \%$ and a remission rate of $27.3 \%$. Only one patient was unable to tolerate the combination, although $50 \%$ had significant side effects during treatment. ${ }^{77}$

This approach has certain disadvantages, ie, it does not allow for adequate evaluation of monotherapy, is associated with reduced compliance, has an increased likelihood of adverse effects, is prone to polypharmacy, and has the potential for increased drug interactions. Advantages of the combination approach are that it is coupled with a rapid response, no titration is necessary, initial improvements are maintained, the strategy builds on therapeutic gains, addition of the second compound is generally well tolerated, and the disadvantages of switching strategies are avoided. In addition, the response rate is comparable or superior to drug substitution. In this strategy, there might be a synergistic therapeutic effect, but side effects due to drug-drug interactions also tend to emerge, so careful drug surveillance is needed. ${ }^{6,69}$

\section{Augmentation strategies}

Augmentation therapy involves adding a second agent (but one that is not routinely regarded as an antidepressant) to the therapeutic regimen when there is only a partial response to the primary antidepressant agent. ${ }^{38}$ The reported strength of recommendation for augmentation or switching is best supporting evidence. ${ }^{78}$ Various augmenting agents, including lithium, atypical antipsychotics, thyroid hormone, pindolol, buspirone, dopamine agonists, sex steroids, glucocorticoidspecific agents, herbal products, and newer anticonvulsants, have been used in patients with treatment-resistant depression. ${ }^{19}$ Augmentation options, mechanisms, and dosing strategies for the various agents are summarized in Tables 5-7. The key points are as follows: downregulation of central beta-adrenergic receptors, which explains the 4-6-week delay in obtaining clinical improvement; lithium enhances not only serotonin neurotransmission but also impacts other neurotransmitter systems and neuromodulators, with a response rate of $30 \%-65 \%$ in patients with treatment-resistant depression who have failed several classes of antidepressants and coupled with equal augmentation efficacy at serum blood levels of 0.4 and $0.8 \mathrm{mEq} / \mathrm{L}$; response may take just 2 days or up to 3-6 weeks, which is considerably shorter than the delay expected with switching, which involves taper of the first drug, washout, and delay in onset of the second drug; antagonism of $5 \mathrm{HT}_{2 \mathrm{~A}}$ receptors, common among atypical antipsychotics, is also seen with mirtazapine and nefazodone and is coupled with enhanced release of frontal dopamine and norepinephrine, which is thought to be a key action of antidepressant agents; fluoxetine-olanzapine reported $40 \%$ improvement among patients with treatment-resistant depression as compared with $30 \%$ and $25 \%$ improvement with fluoxetine and olanzapine alone, respectively; olanzapine, aripiprazole, quetiapine, and ziprasidone had mixed results in a population with treatment-resistant depression; T3 25-50 $\mu \mathrm{g}$ /day for 2-3 weeks is more effective than T4 for augmenting TCA, monoamine oxidase inhibitors, SSRI, and lithium in patients with treatment-resistant depression; monitoring thyroid function before T3 administration for a baseline reading as well as after administration is important; pindolol, a 5-HT postsynaptic antagonist, accelerates the onset of action of antidepressants by preventing negative feedback to the presynaptic $5-\mathrm{HT}_{1 \mathrm{~A}}$ receptor but is currently not recommended for this purpose; unlike open-label studies, buspirone is ineffective in randomized controlled trials; stimulants had no positive results in randomized controlled trials involving patients with treatment-resistant depression; after adjusting for the selection bias inherent in the $S T A R * D$ comparison of augmentation versus switching, clinically meaningful differences in the adverse event profiles between these strategies were not observed; risperidone (remission rate [RR] 26.7\%), valproate (RR 48.7\%), buspirone (RR 32.6\%), trazodone (RR 42.6\%), and thyroid hormone (RR 37.5\%) added to paroxetine $20 \mathrm{mg}$ /day was effective and well tolerated in 225 Chinese patients with stage II treatment-resistant depression; an add-on multicenter trial of 183 patients with treatment-resistant depression failed to detect a statistically significant difference between lamotrigine and placebo given for 10 weeks, but post hoc analysis suggested that future studies of the efficacy of lamotrigine should focus on specific subgroups with depression; a double-blind, placebo-controlled study found that topiramate augmentation potentiates the efficacy of SSRI (fluoxetine, citalopram, sertraline) in the treatment of resistant depression; and further large, comparative, double-blind, randomized clinical trials of augmentation agents in patients with treatment-resistant depression are needed. ${ }^{9,30,79-99}$

The level of evidence for common augmentation agents is as follows: lithium and T3 (best evidence); atypical antipsychotic drugs (some evidence); stimulants, inositol, estrogen, omega-3 fatty acids, and dopamine agonists (little evidence); herbal supplements, lamotrigine (no evidence); and tetraiodothyronine and pindolol (not effective). ${ }^{46}$

\section{Comorbidity}

Patients with treatment-resistant depression need to be assessed for comorbid medical and other psychiatric conditions. This is mandatory because $75.5 \%$ and $46.9 \%$ 
Table 5 Augmentation options for treatment-resistant depression

\begin{tabular}{|c|c|c|}
\hline Medication & Available data & Remarks \\
\hline \multicolumn{3}{|l|}{ Traditional agents } \\
\hline Mirtazapine ${ }^{77}$ & Positive RCTs, ${ }^{77}$ STAR*D & Limited data \\
\hline Bupropion ${ }^{100}$ & Multiple open-label trials, RCTs, STAR*D & Rapidly effective and more data are needed \\
\hline Buspirone ${ }^{96}$ & Negative RCTs, STAR*D & Ineffective in RCTs \\
\hline T3 & $\begin{array}{l}\text { Limited RCTs with SSRI, }{ }^{78,96} \text { positive } \\
\text { when combined with } \mathrm{TCA}^{91,93}\end{array}$ & $\begin{array}{l}\text { Comparable with lithium in STAR*D but fewer } \\
\text { side effects }\end{array}$ \\
\hline Lithium & $\begin{array}{l}\text { Limited RCTs with SSRI, }{ }^{78,80} \text { positive when } \\
\text { combined with } \mathrm{TCA}^{93}\end{array}$ & Comparable to T3 in STAR*D but more side effects \\
\hline Lamotrigine $^{97}$ & Negative RCTs & Small numbers, mixed populations \\
\hline Valproate ${ }^{96}$ & Pilot RCT, effective and well tolerated & Data are limited and larger sample size RCTs are needed \\
\hline Topiramate $^{98}$ & Positive RCT ${ }^{98}$ & RCTs with larger sample needed \\
\hline Pindolo ${ }^{94}$ & Negative RCTs ${ }^{94}$ & $\begin{array}{l}\text { Positive data for antidepressant effect acceleration, } \\
\text { not recommended for augmentation }\end{array}$ \\
\hline Stimulants ${ }^{81}$ & Negative RCTs ${ }^{81}$ & $\begin{array}{l}\text { May have a role for adjunctive treatment of apathy. } \\
\text { Accelerates the antidepressant effect }\end{array}$ \\
\hline Sex hormones & Mixed data, most for testosterone & Significant long-term side effects \\
\hline \multicolumn{3}{|l|}{ Atypical antipsychotics } \\
\hline Aripiprazole ${ }^{89}$ & 3 positive $\mathrm{RCTs},{ }^{89} \mathrm{FDA}$ indication & Negative self-report outcomes \\
\hline Olanzapine/fluoxetine ${ }^{23}$ & $\begin{array}{l}\text { One positive } \mathrm{RCT},{ }^{23} \text { multiple equivocal } \\
\mathrm{RCTs},{ }^{85} \mathrm{FDA} \text { indication }\end{array}$ & Weight gain, metabolic syndrome \\
\hline Quetiapine $^{99}$ & $\begin{array}{l}\text { One negative RCT, two positive unpublished } \\
\text { RCTs with extended-release formulation }\end{array}$ & $\begin{array}{l}\text { Weight gain, metabolic syndrome, helpful adjunctive } \\
\text { agent for some patients with TRD but } \\
\text { placebo-controlled trials are needed }\end{array}$ \\
\hline Risperidone ${ }^{96}$ & Two positive RCTs, one negative & $\begin{array}{l}\text { Trials with short treatment lead-in } \\
\text { ( } 4-5 \text { weeks on previous antidepressant treatment) }\end{array}$ \\
\hline Ziprasidone ${ }^{85}$ & Mixed open-label data only ${ }^{85}$ & \\
\hline All antipsychotics & $\begin{array}{l}\text { Response (odds ratio }=1.69 \text { ) and } \\
\text { remission (odds ratio }=2.00 \text { ) versus } \\
\text { placebo from RCTs }\end{array}$ & $\begin{array}{l}\text { Discontinuation rates for adverse events higher versus } \\
\text { placebo (odds ratio }=3.91 \text { ) }\end{array}$ \\
\hline
\end{tabular}

Note: Information sourced from a number of papers. ${ }^{11,13-14,23,31,77-98,100}$

Abbreviations: RCTs, randomized controlled trials; FDA, Food and Drug Administration; SSRI, selective serotonin reuptake inhibitor; STAR*D, Sequenced Treatment Alternatives to Relieve Depression; TRD, treatment-resistant depression.

of patients with unipolar and bipolar treatment-resistant depression $(n=49)$ were reported to have at least one other Axis I and two additional Axis I diagnoses, respectively, which included anxiety disorder and substance abuse. Axis I comorbidity appears to be differentially associated with treatment resistance in unipolar and bipolar depression. ${ }^{101}$ It is also true with treatment-resistant depression, which is probably associated with a variety of physical diseases at an etiological level, including painful syndromes. ${ }^{102}$ In addition, both physical and psychiatric comorbid conditions contribute to treatment resistance in patients with depression. Patients with comorbidities who showed a partial response to TCA, monoamine oxidase inhibitors, SSRI, and SNRI may derive benefit from the use of stimulants, ie, methylphenidate $10 \mathrm{mg}$ three times daily, dextroamphetamine $5 \mathrm{mg}$ three times daily, or modafinil 100-200 mg once daily. These medications are reported to accelerate the effects of antidepressant therapy, but have a potential for abuse and randomized controlled trials failed to produce any treatment benefits. ${ }^{76,81}$
However, these medications may have a role in the adjunctive treatment of apathy. ${ }^{30,81}$ Nefazodone, another compound used concurrently with prescribed medications in patients with treatment-resistant depression $(\mathrm{n}=20)$ and high psychiatric comorbidity (post-traumatic stress disorder, substance use disorder, and personality disorder) produced good results, with $50 \%$ of patients $(n=11)$ showing substantial improvement, and a smaller proportion having a more modest clinical response. ${ }^{84}$ Duloxetine and venlafaxine have also been used in several studies with fairly good results. ${ }^{103}$ The basic principles of treating treatment-resistant depression with comorbidities remain the same and all options need to be used sequentially. ${ }^{104}$

\section{Electroconvulsive therapy}

ECT is a recognized mode of treatment for a variety of mental disorders, including treatment-resistant depression. ${ }^{105,106}$ ECT is still the most consistently effective in patients with treatment-resistant depression, with a response rate 
Table 6 Mechanism of action of agents used as augmentation for treatment-resistant depression

\begin{tabular}{|c|c|}
\hline Augmentation agent & Mechanism of action \\
\hline Lithium & $\begin{array}{l}\text { Potentiate serotonergic neurotransmission, } \\
\text { modulates phosphatidyl-inositol pathway }\end{array}$ \\
\hline Triiodothyronine & $\begin{array}{l}\text { Potentiate norepinephrine neurotransmission, } \\
\text { corrects subclinical hypothyroidism that } \\
\text { causes depression-like symptoms }\end{array}$ \\
\hline Atypical antipsychotics & $\begin{array}{l}\text { Improve frontal serotonin, norepinephrine, } \\
\text { and dopamine functions, and other } \\
\text { neurotransmitters such as glutamate }\end{array}$ \\
\hline Psychostimulants & $\begin{array}{l}\text { Improve norepinephrine and dopamine } \\
\text { neurotransmission }\end{array}$ \\
\hline Inositol & $\begin{array}{l}\text { Precursor of diacylglycerol and inositol } \\
\text { triphosphate }\end{array}$ \\
\hline Estrogen & $\begin{array}{l}\text { Affects gamma aminobutyric acid, } \\
\text { serotonergic, noradrenergic and cholinergic } \\
\text { neurotransmission }\end{array}$ \\
\hline Omega-3 fatty acids & $\begin{array}{l}\text { Normalize communication in nerve cells; } \\
\text { lower tumor necrosis factor- } \alpha \text {; lower } \\
\text { interleukin-B; lower prostaglandins } \\
\text { E 2, 3, 4; and increase brain-derived } \\
\text { neurotrophic factor }\end{array}$ \\
\hline Dopamine agonists & Increase dopamine tone \\
\hline Herbal supplements & $\begin{array}{l}\text { May impact monoaminergic } \\
\text { neurotransmission }\end{array}$ \\
\hline Lamotrigine & $\begin{array}{l}\text { Blocks } 5 \text {-hydroxytriptamine } 3 \text { receptors, } \\
\text { potentiates dopamine }\end{array}$ \\
\hline Tetraiodothyronine & $\begin{array}{l}\text { Potentiates norepinephrine } \\
\text { neurotransmission }\end{array}$ \\
\hline Pindolol & Increases serotonergic tone \\
\hline
\end{tabular}

Copyright $\odot$ 2005, MBL Communications. Adapted with permission from Gotto J. Rapaport MH. Treatment options in treatment-resistant depression. Prim Psychiatry. $2005 ; 12: 42-50.46$

of $50 \%-70 \%{ }^{30}$ Furthermore, ECT remains the treatment of first choice for the most severe, incapacitating forms of treatment-resistant depression, though the strength of the recommendation of ECT is level C. ${ }^{78}$ Surprisingly, relapse rates are significantly higher in patients with treatmentresistant depression after a successful course of therapy. ${ }^{107}$ Research is needed to establish the efficacy of alternative methods to prevent relapse following successful ECT, including maintenance ECT and combination pharmacotherapy strategies. Patients who fail to respond to ECT as proposed in Stage 5 treatment-resistant depression represent some of the most challenging cases. Predictors of nonresponse to ECT need to be in place. In a large patient population with treatment-resistant depression, ECT was an effective treatment for approximately two thirds of cases. A lack of response to ECT was associated with bipolar subtype, presence of manic symptoms during depression, slightly less severe depressive symptomatology, and protracted duration of the depressive episode. ${ }^{108}$ In a recent study of adolescents with treatment-resistant depression, continuation ECT and maintenance ECT were useful and safe treatment strategies for selected adolescents with severe treatment-resistant depression, and symptom remission was achieved without cognitive impairment. ${ }^{109}$

\section{Other somatic therapies}

These reversible but more invasive therapies were developed to avoid the adverse effects and complications of ECT and at the same time to be more effective in treatment-resistant depression. rTMS and VNS are approved by the US Food and Drug Administration for the treatment of intractable seizure disorders and treatment-resistant depression. However, with regard to treatment-resistant depression, other neuromodulation therapies, including DBS, magnetic seizure therapy, and tDCS, are in the experimental stages. ${ }^{30,88,110-112}$ Notably, the Food and Drug Administration has approved DBS for compassionate use in severe obsessive-compulsive disorder.

Studies of somatic therapies seem to be producing promising results. In an open-label study, 21 patients who failed two antidepressant trials were given rTMS therapy (high-frequency, $10 \mathrm{~Hz}$, intensity of $110 \%$ ) for 4 weeks, keeping the dose of pre-existing antidepressants unchanged. Nineteen patients completed the study and were assessed. In intention-to-treat analysis, the mean HRSD-17 scores were reduced from $30.80 \pm 5.00$ to $19.00 \pm 6.37$. Only four patients reported headache, but there was no discontinuation due to adverse effects. The study indicated the potential utility of rTMS as an augmenting agent in treatmentresistant depression. Both high frequency left-sided and low frequency right-sided unilateral rTMS are efficacious in treatment-resistant depression. Similar benefits have been suggested for sequential bilateral rTMS (low frequency right-sided then high frequency left-sided). ${ }^{113} \mathrm{In}$ another study, subjects aged 18-85 years were recruited from a tertiary care university hospital. Seventy-four subjects with treatment-resistant depression and a 17-item HRSD score greater than 21 were randomized to receive unilateral, bilateral, or sham rTMS. The rates of remission were compared between the three treatment groups. The remission rates differed significantly between the groups using a modified intention-to-treat analysis that excluded subjects who did not respond to ECT during the current episode. The remission rate was significantly higher in the bilateral group than in the sham group. The remission rate in the unilateral group did not differ in either group. ${ }^{114}$ These studies, including a meta-analysis, call for larger controlled studies to compare the efficacy of sequential bilateral rTMS and high frequency 
Table 7 Dosing strategies for augmentation agents for treatment-resistant depression

\begin{tabular}{|c|c|c|}
\hline Augmentation agents & Recommended dosing strategies & Side effects \\
\hline Lithium & $\begin{array}{l}\text { Initially } 150 \mathrm{mg} \text { twice daily to be increased in accordance } \\
\text { with blood level }(0.4-0.8 \mathrm{mEq} / \mathrm{L}) \text { and clinical response }\end{array}$ & Tremors, weight gain, polydipsia, polyurea \\
\hline Triiodothyronine & $25-50 \mu \mathrm{g} /$ day for 3 weeks & Irritability, sweating, palpitation, and anxiety \\
\hline Olanzapine & $2.5-5 \mathrm{mg} /$ day & Sedation and weight gain \\
\hline Ziprasidone & $20-40 \mathrm{mg} /$ day & Sedation and weight gain \\
\hline Risperidone & $0.5-1 \mathrm{mg} /$ day & Sedation and weight gain \\
\hline Methylphenidate & $5-30 \mathrm{mg} /$ day & $\begin{array}{l}\text { Insomnia, irritability, Gl symptoms, abuse } \\
\text { and blood pressure/heart rate variability }\end{array}$ \\
\hline Dextroamphetamine & $10-20 \mathrm{mg} /$ day & $\begin{array}{l}\text { Insomnia, irritability, Gl symptoms, abuse } \\
\text { and blood pressure/heart rate variability }\end{array}$ \\
\hline Modafinil & $200 \mathrm{mg} /$ day & Headache, dizziness, nausea and dry mouth \\
\hline Primapexole & $0.25-2.5 \mathrm{mg} / \mathrm{day}$ & Nausea and agitation \\
\hline Inositol & $500-1000 \mathrm{mg} /$ day & Not available \\
\hline Estrogen & $0.1-0.2 \mathrm{mg}$ patch & $\begin{array}{l}\text { Risk for breast and uterine cancer, } \\
\text { weight gain, and edema }\end{array}$ \\
\hline Omega-3 fatty acids & $6 \mathrm{~g}$ EPA and $2 \mathrm{~g}$ DHA & Unpleasant fishy burp \\
\hline Lamotrigine & $\begin{array}{l}12.5-25 \mathrm{mg} / \text { day initially; increase by } 12.5-25 \mathrm{mg} / \text { week } \\
\text { up to } 100-220 \mathrm{mg} / \text { day }\end{array}$ & $\begin{array}{l}\text { Nausea, headache, blurry vision, } \\
\text { rash and sleepiness }\end{array}$ \\
\hline
\end{tabular}

Notes: Pindolol, T4, and herbal supplements are not recommended.

Copyright (C) 2005, MBL Communications. Adapted with permission from Gotto J, Rapaport MH. Treatment options in treatment-resistant depression. Prim Psychiatry. 2005; I2:42-50.46 Abbreviations: DHA, docosahexaenoic acid; EPA, eicosapentaenoic acid; GI, gastrointestinal.

left-sided rTMS in depression and treatment-resistant depression. ${ }^{114,115}$

In another study, 22 patients with major depression were randomly assigned to a crossover protocol comparing tDCS and placebo stimulation add-on to a stable antidepressant medication. The parameters of active tDCS were: $1 \mathrm{~mA}$ or $2 \mathrm{~mA}$ for 20 minutes daily, with the anode over the left dorsolateral prefrontal cortex and the cathode over the contralateral supraorbital region. Active and placebo tDCS was applied for 2 weeks using indistinguishable direct current stimulators. Patients, raters, and operators were blinded to the treatment conditions. The results showed that there was no significant difference in depression scores after 2 weeks of real tDCS compared with 2 weeks of sham tDCS. However, subjective mood ratings showed an increase in positive emotions after real tDCS compared with sham tDCS. Anodal tDCS, applied for 2 weeks, was not superior to placebo in patients with treatmentresistant depression. A modified and improved tDCS protocol should be investigated in controlled pilot trials to develop effective tDCS for treatment-resistant depression. ${ }^{116}$

In an interesting single treatment-resistant depression patient analysis, VNS produced good results and achieved a cost saving over modified ECT. ${ }^{117}$ Both ECT and VNS could be combined in managing severe cases of treatment-resistant depression. VNS has some disadvantages, including hoarseness of voice caused by the stimulator delivering the electrical pulse, and rarely infection due to surgical implantation of a small device into the left chest wall. ${ }^{117}$ In an open-label study of resistant major depressive episode, the predictors of response to VNS were a history of resistant depression, mild to moderate resistant depression, non-severe resistant depression, and no history of use of ECT. ${ }^{118}$ The long-term effects and tolerability of VNS need to be determined to ascertain its suitability for use in treatment-resistant depression.

A multicenter pilot study of 21 patients with treatmentresistant depression who received DBS found that patients treated with subcallosal cingulate gyrus DBS had an RESP 50 of $57 \%$ at one month, $48 \%$ at 6 months, and $29 \%$ at 12 months. However, the response rate after 12 months of DBS increased to $62 \%$ when response is defined by $50 \%$ reduction in baseline HRSD-17 score (RESP50). Reductions in depressive symptoms were associated with amelioration of disease severity in patients who responded to surgery. Overall, findings from this study corroborated the results of previous reports showing that outcome of subcallosal cingulate gyrus DBS may be replicated across centers. ${ }^{119}$ Ward and Irazoqui have provided greater detail on target structures, motivation, response rates, and the proposed mechanism of action of somatic therapies used in treatmentresistant depression. ${ }^{4}$ Data from a follow-up study suggested that in the long term (up to 6 years), DBS remains a safe and effective treatment for treatment-resistant depression. ${ }^{120}$ Finally, psychosurgery, such as subcaudate tractotomy, limbic leucotomy, anterior capsulotomy, and anterior cingulotomy remain the last line of somatic treatment for patients with severe treatment-resistant depression. ${ }^{30}$ 


\section{Complementary and alternative medicine}

The therapeutic role of ethyl eicosapentaenoic acid, an essential fatty acid, as an augmentation agent for traditional antidepressants in treatment-resistant depression has been reported.$^{30}$ Puri et al showed that eicosapentaenoic acid improved some symptoms, including suicidal ideation and social phobia, in a single patient with severe treatmentresistant depression. This compound also induced neurobiological changes, such as a $30 \%$ increase in the volumetric niacin response, a $53 \%$ increase in the relative concentration of cerebral phosphomonoesters, a $79 \%$ increase in the ratio of cerebral phosphomonoesters to phosphodiesters, and a reduction in the lateral ventricular volume of the brain. ${ }^{121}$ The therapeutic value of L-methylfolate, a medicinal food, is emphasized in patients of Hispanic origin with treatmentresistant depression. ${ }^{122}$ The efficacy of other complementary and alternative medicines in patients with treatment-resistant depression needs to be studied because these therapies have minimal adverse effects and their contribution to the management of various diseases is expanding rapidly. Conversely, in modern medicine, of about $65 \%$ of patients who discontinue antidepressants, $45 \%$ of them do so because of unpleasant side effects. ${ }^{123}$ Regarding lifestyle changes, researchers reported positive effects of moderate physical exercise on quality of life in patients with treatment-resistant depression. ${ }^{124}$

\section{Psychotherapy}

In general, psychotherapy alone is effective in mild to moderate depression, and when combined with antidepressants, is associated with better results in severe depression than either therapy alone. Traditionally, the strength of recommendation for psychotherapy is B level, and it has been considered useful in the management of treatment-resistant depression, primarily as an adjunct to help patients maintain morale and optimism. ${ }^{78}$ Currently, various studies have also justified the use of psychotherapy, especially cognitive behavior therapy, when using switching and augmentation approaches in patients with treatment-resistant depression. ${ }^{9,30,100}$ In a comparative study that recruited patients with treatment-resistant depression who responded unsatisfactorily to citalopram and were assigned randomly to either augmentation of citalopram with cognitive therapy or sustained-release bupropion or buspirone or switch to cognitive therapy or another antidepressant, sertraline, sustained-release bupropion, or extendedrelease venlafaxine, Thase et $\mathrm{al}^{100}$ found that pharmacologic augmentation was more rapidly effective than augmentation of citalopram using cognitive behavioral therapy, whereas switching to cognitive behavioral therapy was better tolerated than switching to a different antidepressant. Few randomized controlled trials ${ }^{125,126}$ have investigated interventions for treatment-resistant depression in young people, and results from these show modest benefit from antidepressants, with no additional benefit of cognitive behavioral therapy over medication. Overall, there is a lack of evidence about effective interventions to treat young people who have failed to respond to evidence-based interventions for depression. Research in this area is urgently required. ${ }^{125,126}$ In a related development, research suggests that children and adolescents with school difficulties are less likely to respond to fluoxetine compared with those with no school difficulties. Depressed adolescents in the Treatment of Resistant Depression in Adolescents study, who had not responded to a previous adequate trial of an SSRI, were randomly assigned to one of the following: another SSRI, venlafaxine, another SSRI + cognitive behavioral therapy, or venlafaxine + cognitive behavioral therapy. Participants were classified into four groups, depending on whether their enrollment in the study and end of treatment was during school or summer vacation. There was a significant interaction between school difficulties and timing of treatment, with the lowest rates of response being among adolescents having school difficulties and ending their treatment during the active school year. School problems are relevant to treatment response in depressed adolescents and should be incorporated into the treatment plan. These findings also suggest that the time of year might need to be taken into consideration for analysis of clinical trials in school-aged youth. ${ }^{127}$ In a systematic review, ${ }^{128}$ researchers examined the utility of psychotherapy in the management of treatment-resistant depression, and found it to be useful. However, the evidence was sparse and the results were mixed. Given that quality trials are lacking, rigorous clinical trials are recommended to guide practice, including in primary care. ${ }^{128}$

A team of researchers examined the long-term outcome of participants in the Treatment of SSRI-Resistant Depression in Adolescents, in which 334 adolescents with major depressive disorder initially resistant to SSRI treatment were randomly treated for 12 weeks with another SSRI, venlafaxine, another SSRI + cognitive behavioral therapy, or venlafaxine + cognitive behavioral therapy. Responders then continued with the same treatment through week 24 , while non-responders were given open treatment. By 72 weeks, an estimated $61.1 \%$ of the randomized adolescents had reached remission. Randomly assigned treatment, ie, that given for the first 12 weeks, 
did not influence the remission rate or time to remission, but the group assigned to SSRI had a more rapid decline in self-reported depressive symptoms and suicidal ideation than those assigned to venlafaxine. Participants with more severe depression, greater dysfunction, and alcohol or drug use at baseline were less likely to remit. The depressive symptom trajectory of the remitters diverged from that of non-remitters during the first 6 weeks of treatment. Of the 130 participants in remission at week 24, 25.4\% relapsed in the subsequent year. While most adolescents achieved remission, more than one third did not, and one quarter of the patients who remitted experienced a relapse. The investigators suggested more effective interventions are needed for patients who do not show robust improvement early on in treatment. ${ }^{129}$

\section{Future treatment options}

New drugs approved for the management of depression are on the market (Table 8). These medications include desvenlafaxine (an SNRI), escitalopram (an SSRI), and a reformulation of trazodone (Oleptro ${ }^{\mathrm{TM}}$ ). A number of drugs, including riluzole, that act on glutamate receptors and have antidepressant activity have also been developed and are approved for managing major depression. ${ }^{81,130}$ Studies have explored the role of ketamine, an NMDA antagonist, in treating treatment-resistant depression and acute suicidal ideation.

Table 8 Future treatment options for treatment-resistant depression

\begin{tabular}{|c|c|}
\hline Medication/intervention & Comments \\
\hline $\begin{array}{l}\text { Melatonin drugs } \\
\text { (agomelatine) }\end{array}$ & $\begin{array}{l}\text { Preliminary data only, no inclusion of } \\
\text { TRD population in registration trials, } \\
\text { not yet studied as an augmenting agent }\end{array}$ \\
\hline $\begin{array}{l}\text { Acetylcholine drugs } \\
\text { (scopolamine, mecamylamine, } \\
\text { varenicline) }\end{array}$ & $\begin{array}{l}\text { Intravenous infusions used for } \\
\text { scopolamine, studied as augmenting } \\
\text { agents rather than primary treatment, } \\
\text { small numbers in published results, } \\
\text { large trials underway }\end{array}$ \\
\hline $\begin{array}{l}\text { Glutamate drugs } \\
\text { (ketamine, NR2 antagonists, } \\
\text { riluzole) }\end{array}$ & $\begin{array}{l}\text { Short-term symptomatic relief, only } \\
\text { intravenous infusions used, further } \\
\text { trials underway }\end{array}$ \\
\hline Neurostimulation & $\begin{array}{l}\text { VNS approved for TRD but long-term } \\
\text { treatment needed, TMS showed less } \\
\text { efficacy in more treatment-resistant } \\
\text { patients but use of TMS in TRD under } \\
\text { investigation, DBS trials underway }\end{array}$ \\
\hline
\end{tabular}

Copyright @ 2010, Informa Healthcare. Adapted with permission from Philip NS, Carpenter LL, Tyrka AR, Price LH. Pharmacologic approaches to treatment resistant depression: a re-examination for the modern era. Expert Opin Pharmacother. 2010;11: 709-722. ${ }^{81}$

Abbreviations: NR2, NMDA receptor subunit; TRD, treatment-resistant depression; VNS, vagus nerve stimulation; DBS, deep brain stimulation; TMS, transcranial magnetic stimulation.
Ketamine appears to have a rapid antidepressant effect, within hours or a day, although these effects only last for 7-10 days. Patients need to be admitted to hospital to receive ketamine intravenously from an anesthesiologist, while their vital signs are closely monitored. Ketamine is a drug of abuse and induces trance-like or hallucinatory states. Like other anesthetics, ketamine also produces mild to moderate cognitive side effects. Ketamine treatment may be akin to ECT and studying ketamine may reveal mechanisms underlying depression and help to identify drugs that can be prescribed as antidepressants to a wider patient population. ${ }^{131}$ In a comparative study of 17 patients with treatment-resistant depression non-responsive to ECT and 23 patients with treatment-resistant depression who had not previously received ECT were given a single open-label infusion of ketamine $0.5 \mathrm{mg} / \mathrm{kg}$ and evaluated using the Montgomery-Åsberg Depression Rating Scale at baseline (60 minutes before the infusion), as well as at 40, 80, 120, and 230 minutes after infusion. Depressive symptoms were significantly improved in the ECT-resistant group at 230 minutes, with a moderate effect size. At 230 minutes, the group not exposed to ECT showed significant improvement with a large effect size. Ketamine appears to improve depressive symptoms in patients with major depression who had previously not responded to ECT. These preliminary results warrant further investigation in a larger sample size to determine the effectiveness of ketamine in patients with depression not responsive to other treatments. ${ }^{132}$ In one study, 10 participants with treatment-resistant depression were given riluzole, another NMDA antagonist, along with their regular antidepressant. After 6-12 weeks, they experienced an almost 10-point drop on the HRSD. ${ }^{130}$

Triple reuptake inhibitors that block the reuptake of serotonin, norepinephrine, and dopamine, are the newest drugs in the stable of monoamine antidepressants. ${ }^{133}$ Currently, there are no randomized controlled trials on these agents and research is preliminary. It is believed that triple reuptake inhibitors devoid of an effect on sexual function could be used as second-line treatment when patients with depression do not respond to an SSRI. ${ }^{134,135}$ Non-conventional antidepressants, such as tianeptine, are also used for treatmentresistant depression with some benefits. ${ }^{133}$ Another new drug, agomelatine, the first melatonergic antidepressant containing a $5-\mathrm{HT}_{2 \mathrm{C}}$ receptor antagonist and a melatonin-1 agonist, is approved in Europe to treat major depression. It has a unique mechanism of action by targeting the melatonin system in the brain, ${ }^{81}$ and randomized controlled trials in the treatmentresistant depression population are needed. In another 
development, loss of brain-derived neurotrophic factor was found in major depression. Brain-derived neurotrophic factor is a member of the nerve growth factor family, which helps with the survival and growth of neurons. However, stress seems to decrease levels of brain-derived neurotrophic factor. Increasing brain-derived neurotrophic factor may be a new strategy for developing new antidepressants. Furthermore, compounds that influence the endocannabinoid system involved in depression, and neuropeptide systems, such as galanin and melanin-concentrating hormone, may be used in the treatment of treatment-resistant depression. ${ }^{133}$ Several neuropeptides and their receptors have also been identified as potential targets for pharmacologic intervention by corticotropin-releasing factor and substance P. ${ }^{136}$ Some investigators have suggested use of Sertoli cell therapy in patients with treatment-resistant depression. ${ }^{137}$ Acetylcholine drugs, such as scopolamine, mecamylamine, and varenicline, have been used in small studies involving patients with treatment-resistant depression, with positive results. ${ }^{81,138,139}$

In summary, preliminary data for the aforementioned newer antidepressant therapies support the view that larger, randomized, controlled studies are needed in future. A stepwise treatment algorithm for patients with treatment-resistant depression need to be used for better decision-making, better responses, and a higher remission rate in the population with treatment-resistant depression. ${ }^{11,140}$

\section{Discussion}

This paper is a narrative review of the literature on treatmentresistant depression. In addition to Google Scholar and Quertle database searches, multiple rounds of computer searching of PubMed using key words and a combined strategy might have led to some relevant articles, especially in young and elderly populations, having been missed, and possibly biasing our results. However, the astronomical database on treatment-resistant depression published regularly and globally is difficult to synthesize. Furthermore, selection and review of all articles by a lone author is an uphill task and selection bias might have entered into this qualitative review. Despite these caveats, this review reports important findings and developments in the therapeutic paradigms for treatment-resistant depression over two decades. The prevalence of treatment-resistant depression is $10 \%-30 \%,{ }^{7}$ but some researchers have suggested that it could be more than $30 \%,{ }^{11,12,69}$ according to definitions of treatment-resistant depression and other methodological issues. With advances in the treatment of resistant depression, it is not surprising that its prevalence would temporally decrease or change.
It seems that depression should only be considered drugresistant after at least 6 weeks of two trials of antidepressant therapy. ${ }^{9,51}$ Some researchers suggested extending this period for up to 10-12 weeks in patients who respond partially to trials of antidepressant therapy. ${ }^{15,47}$ Nonetheless, at least $30 \%$ of patients continue to manifest residual symptoms with poor quality of life and impairment in overall functioning. ${ }^{51}$ In addition to requiring several recommended therapeutic options, this core group of patients with treatment-resistant depression warrants a comprehensive search for factors responsible for the persistence of depression, which include but are not limited to the patient's characteristics and environment, including stresses, a comorbid psychiatric or somatic disorder, and drug abuse or addiction. ${ }^{19,40-42,44,45}$ Arguably, the suggested therapeutic strategies for treatmentresistant depression have variable outcomes in terms of response and remission rate, as well as disadvantages due to multiple factors, including the adverse effect profile of antidepressants.

It is reported that optimization of a first-line antidepressant in adequate doses and for an extended period of up to 12 weeks is based on weak evidence. ${ }^{19,69,81}$ Similarly, trials comparing continuation of the first-line antidepressant versus switching to another antidepressant from a different class have reported conflicting results. ${ }^{9,19}$ A switching strategy may benefit a small proportion of patients, but the elimination half-life of the discontinued drug, such as fluoxetine, and washout period must be taken into account to limit the risk of interactions during the transition period. ${ }^{9,19,69,81}$ A combination approach also has some disadvantages because it increases the risk of adverse effects, possibly without a substantial clinical benefit. ${ }^{19}$ Evidently, a second course of antidepressant monotherapy tends to treat up to $50 \%$ of those who have failed with the initial treatment effectively, when the second drug has a profile distinct from the initial medication. It means that $25 \%$ of patients with treatment-resistant depression respond to optimization and combined strategies, and another $50 \%$ tend to respond to switching options. The remaining $25 \%$ of patients with treatment-resistant depression are candidates for augmentation strategies. ${ }^{81}$

The strength of evidence supporting a trial of augmentation or a switch to a new agent is very similar, with remission rates of $25 \%-50 \%$ in both cases. ${ }^{141} \mathrm{~A}$ review of comparative trials suggested that adjunctive use of lithium and thyroid hormone have an established antidepressant effect in patients with treatment-resistant depression, but there is no firm evidence that adding lithium to non-TCA treatment increases the chances of remission. ${ }^{78,91,93,96,141}$ 
According to other researchers, thyroid hormone, a benzodiazepine, buspirone, and pindolol as augmenting agents have limited proven antidepressant effects. ${ }^{19,78,94,96}$ Furthermore, Connolly and Thase ${ }^{141}$ as well as others ${ }^{46,78,96}$ have reported that of these two options, ie, lithium versus thyroid hormone, T3 augmentation seems to offer the best benefit/risk ratio for augmentation of modern antidepressants. However, lithium is known to have a narrow therapeutic window and needs blood level monitoring to avoid the toxicity and fatalities associated with high lithium levels. ${ }^{77,78,80}$ With regard to newer generations of antidepressants, after failure of a first-line SSRI, neither a switch within a class nor a switch to a different class of antidepressant is unequivocally supported by the data, although switching from an SSRI to venlafaxine or mirtazapine may potentially offer greater benefits. ${ }^{75-77,141}$ In an open-label study, mirtazapine was effective in $38 \%$ of patients with depression resistant to standard antidepressants. ${ }^{142}$ It is noted that switching from a newer antidepressant to a TCA after a poor response to the former is not supported by strong evidence. ${ }^{142}$ Augmentation with an antiepileptic or a psychostimulant is not supported unequivocally but they are reported to be more harmful than beneficial because of adverse effects, including the addiction potential of stimulants. ${ }^{46,81,96-98}$ Conversely, the use of psychostimulants with conventional antidepressants is recommended in patients with treatment-resistant depression because significant improvement was demonstrated, in particular with respect to energy, mood, and psychomotor activity. It was concluded that their rapid onset of action (2-3 hours) after administration may help cover the therapeutic latency period of conventional antidepressants and probably potentiates their effect. ${ }^{143}$ According to some studies, augmentation with atypical antipsychotics has had mixed results, ${ }^{23,85,96}$ but quetiapine and aripiprazole were relatively supported by the evidence. ${ }^{89,99}$ It is noted that Symbyax ${ }^{\circledR}$, a combination of olanzapine and fluoxetine, is approved for the acute management of treatment-resistant depression.

ECT has a place in the management of patients failing multiple optimized monotherapies, switching options, combined approaches, and augmented treatment strategies $^{30,105,106,108}$ but carries a risk of reversible memory disorders. ${ }^{19}$ Surprisingly, patients with treatment-resistant depression who responded to ECT were found to have a high relapse rate, ${ }^{107}$ which could be prevented by maintenance ECT. Some studies reported no cognitive impairment with ECT in adolescents with treatment-resistant depression. ${ }^{109}$ In this regard, replication research is required to support or refute such results. The role of other somatic interventions, including VNS, rTMS, DBS, and tDCS, in patients with treatment-resistant depression is expanding with greater efficacy, but have some side effects and need further research, especially large controlled randomized studies targeting particular areas in the brain implicated in major depression and treatment-resistant depression. ${ }^{4,112-120}$ The efficacy of psychotherapy in patients with treatment-resistant depression is fairly good, and 50\% of patients tend to get benefits from psychotherapies, especially cognitive behavioral therapy and mindfulness-based cognitive behavioral therapy. ${ }^{19,100,144}$ Additional cognitive behavioral therapy in the young population with treatment-resistant depression has limited or no value and needs further research. ${ }^{126}$ Regular exercise and use of some complementary and alternative medicines impact positively on treatment-resistant depression and need further research using herbal supplements. ${ }^{124}$

\section{Conclusion}

In summary, $70 \%$ of patients with major depression respond to initial antidepressant therapy, leaving $30 \%$ of patients who are refractory to treatment and therefore need special treatment-resistant depression management strategies. Twenty-five percent of patients with treatment-resistant depression tend to respond to optimization and combined treatment paradigms and another $50 \%$ of patients are reported to respond to switching therapeutic options. Augmentation strategies target the remaining $25 \%$ of patients suffering from treatment-resistant depression, with inconsistent outcomes. Overall, although there is no strict compartmentalization of treatment response and remission rate in the population with treatment-resistant depression, about one third of patients with the disorder continue to be resistant to available therapeutic options, and hence pose a major therapeutic challenge to mental health experts.

\section{Recommendations}

Based on this narrative review, that has some caveats, the following recommendations are made:

- Each individual with treatment-resistant depression is a unique case and needs detailed evaluation to identify the prior antidepressant response and also to make a correct diagnosis.

- Assessment of risk factors for treatment-resistant depression is equally important to guide mental health professionals in tailoring an appropriate management plan for patients with treatment-resistant depression.

- There are a wide variety of options for the treatment of major depression and treatment-resistant depression, 
therefore every therapeutic paradigm needs to be utilized when helping patients with treatment-resistant depression.

- In light of the demonstrated importance of truly adequate treatment to the long-term outcomes of patients with treatment-resistant depression, further randomized clinical trials involving newer drugs and psychotherapies and somatic therapies are needed in the future.

\section{Acknowledgment}

I would like to express my sincere thanks to Abdullah Al-Anaizi, Dean of the College of Applied Medical Sciences, King Saud Bin Abdulaziz University for Health Sciences, for revising the earlier draft of this manuscript. Also special thanks is extended to Naseem Akhtar Qureshi for revising and editing this manuscript in accordance with the reviewers' comments.

\section{Disclosure}

The author reports no conflicts of interest in this work.

\section{References}

1. Souery D, Amsterdam J, deMontigny C, et al. Treatment resistant depression: methodological overview and operational criteria. Eur Neuropsychopharmacol. 1999;9:83-91.

2. O'Reardon JP, Amsterdam JD. Treatment-resistant depression: progress and limitations. Psychiatr Ann. 1998;28:633-640.

3. Nelson JC. Combined drug treatment strategies for major depression. Psych Ann. 1998;28:197-202.

4. Ward MP, Irazoqui PP. Evolving refractory major depressive disorder diagnostic and treatment paradigms: toward closed-loop therapeutics. Front Neuroeng. 2010;3:7.

5. American Psychiatric Association. Practice Guideline for the Treatment of Patients with Major Depression, 2000. Diagnostic and Statistical Manual of Mental Disorders, 4th Edition, Text Revision. Washington, DC: American Psychiatric Association; 2000.

6. Cadieux RJ. Practical management of treatment-resistant depression. Am Fam Physician. 1998;58:2059-2062.

7. Joffe RT, Levitt AJ, Sokolov ST. Augmentation strategies. J Clin Psychiatry. 1996;57:25-31.

8. Sackeim HA. The definition and meaning of treatment-resistant depression. J Clin Psychiatry. 2001;62:10-17.

9. Thase ME, Rush JA. Treatment-resistant depression. In: Bloom FE, Kupfer DJ, editors. Psychopharmacology. New York, NY: Raven; 1995.

10. Keller MB. Issues in treatment-resistant depression. J Clin Psychiatry. 2005;66 Suppl 8:5-12.

11. National Institute of Mental Health. Sequenced Treatment Alternatives to Relieve Depression (STAR*D) Study. Available from: http://www. nimh.nih.gov/trials/practical/stard/index.shtml. Accessed March 12, 2012.

12. Kennedy SH, Giacobbe P. Treatment resistant depression - advances in somatic therapies. Ann Clin Psychiatry. 2007;19:279-287.

13. Huynh NN, McIntyre RS. What are the implications of the STAR*D trial for primary care? A review and synthesis. Prim Care Companion J Clin Psychiatry. 2008;10:91-96.

14. Cain RA. Navigating the Sequenced Treatment Alternatives to Relieve Depression (STAR*D) study: practical outcomes and implications for depression treatment in primary care. Prim Care. 2007;34:505-519.
15. Sakolsky DJ, Perel JM, Emslie GJ, et al. Antidepressant exposure as a predictor of clinical outcomes in the Treatment of Resistant Depression in Adolescents (TORDIA) study. J Clin Psychopharmacol. 2011;31:92-97.

16. Fava M, Katharine G, Davidson BA. Definition and epidemiology of treatment-resistant depression. Psychiatr Clin North Am. 1996;19: 179-200.

17. Thase ME, Rush AJ. When at first you don't succeed: sequential strategies for antidepressant nonresponders. J Clin Psychiatry. 1997;58 Suppl 13:23-29.

18. Cowen PJ. Pharmacological management of treatment-resistant depression. Advances in Psychiatric Treatment. 1998;4:320-327.

19. [No authors listed]. Treatment-resistant depression: no panacea, many uncertainties. Adverse effects are a major factor in treatment choice. Prescrire Int. 2011;20:128-133.

20. Ruhé HG, van Rooijen G, Spijker J, Peeters FP, Schene AH. Staging methods for treatment-resistant depression. A systematic review. J Affect Disord. 2012;137:35-45.

21. Fekadu A, Wooderson SC, Rane LJ, Markopoulou K, Poon L, Cleare AJ. Long-term impact of residual symptoms in treatmentresistant depression. Can J Psychiatry. 2011;56:549-557.

22. Asarnow JR, Porta G, Spirito A, et al. Suicide attempts and nonsuicidal self-injury in the treatment of resistant depression in adolescents: findings from the TORDIA study. JAm Acad Child Adolesc Psychiatry. 2011;50:772-781.

23. Degenhardt EK, Jamal HH, Tormey S, Case M. Early weight gain as a predictor of substantial weight gain with olanzapine/fluoxetine combination: an analysis of 2 adult studies in treatment-resistant depression. J Clin Psychopharmacol. 2011;31:337-340.

24. Bosmans JE, de Bruijne MC, de Boer MR, van Hout H, van Steenwijk P, van Tulder MW. Health care costs of depression in primary care patients in The Netherlands. Fam Pract. 2010;27:542-548.

25. Simon GE, Revicki D, Heiligenstein J, et al. Recovery from depression, work productivity, and health care costs among primary care patients. Gen Hosp Psychiatry. 2000;22:153-162.

26. Tierney JG II. Treatment-resistant depression: managed care considerations. J Manag Care Pharm. 2007;13 Suppl SA:S2-S7.

27. Parikh RM, Lebowitz BD. Current perspectives in the management of treatment-resistant depression. Dialogues Clin Neurosci. 2004; 6:53-60.

28. Greenberg P, Corey-Lisle PK, Birnbaum H, Marynchenko M, Claxton A. Economic implications of treatment-resistant depression among employees. Pharmacoeconomics. 2004;22:363-373.

29. Lynch FL, Dickerson JF, Clarke G, et al. Incremental cost-effectiveness of combined therapy vs medication only for youth with selective serotonin reuptake inhibitor-resistant depression: treatment of SSRIresistant depression in adolescents trial findings. Arch Gen Psychiatry. 2011;68:253-262.

30. Shelton RC, Osuntokun O, Heinloth AN, Corya SA. Therapeutic options for treatment-resistant depression. CNS Drugs 2010;24:131-161.

31. Rush AJ, Warden D, Wisniewski SR, et al. STAR*D: revising conventional wisdom. CNS Drugs. 2009;23:627-647.

32. Thase ME. Treatment-resistant depression: prevalence, risk factors, and treatment strategies. J Clin Psychiatry. 2011;72:e18.

33. Fava M, Rappe SM, Pava JA, Nierenberg AA, Alpert JE, Rosenbaum JF. Relapse in patients on long-term fluoxetine treatment. J Clin Psychiatry. 1995;56:52-55.

34. Culpepper L. Why do you need to move beyond first-line therapy for major depression? J Clin Psychiatry. 2010;71 Suppl 1:4-9.

35. Antai-Otong D. The art of prescribing. Monotherapy antidepressant: a thing of the past? Implications for the treatment of major depressive disorder. Perspect Psychiatr Care. 2007;43: $142-145$.

36. Dunner DL, Rush AJ, Russell JM, Burke M, Woodard S, Wingard P, Allen J. Prospective, long-term, multicenter study of the naturalistic outcomes of patients with treatment-resistant depression. J Clin Psychiatry. 2006;67:688-695. 
37. Phillips KA, Nierenberg AA. The assessment and treatment of refractory depression. J Clin Psychiatry. 1994;55:20-26.

38. Vieta E, Colom F. Therapeutic options in treatment-resistant depression. Ann Med. 2011;43:512-530.

39. Kostanjsek N. Use of The International Classification of Functioning, Disability and Health (ICF) as a conceptual framework and common language for disability statistics and health information systems. $B M C$ Public Health. 2011;11 Suppl 4:53.

40. Maalouf FT, Atwi M, Brent DA. Treatment-resistant depression in adolescents: review and updates on clinical management. Depress Anxiety. 2011;28:946-954.

41. Shamseddeen W, Asarnow JR, Clarke G, et al. Impact of physical and sexual abuse on treatment response in the Treatment of Resistant Depression in Adolescent Study (TORDIA). J Am Acad Child Adolesc Psychiatry. 2011;50:293-301.

42. Serretti A, Chiesa A, Calati R, et al. A preliminary investigation of the influence of CREB1 gene on treatment resistance in major depression. J Affect Disord. 2011;128:56-63.

43. Zhang X, Beaulieu JM, Sotnikova TD, Gainetdinov RR, Caron MG. Tryptophan hydroxylase-2 controls brain serotonin synthesis. Science. 2004;305:217.

44. Zhang X, Gainetdinov RR, Beaulieu JM, et al. Loss-of-function mutation in tryptophan hydroxylase-2 identified in unipolar major depression. Neuron. 2005;45:11-16

45. Baud P. Risk factors and psychosocial disability of treatment resistant depression. Rev Med Suisse. 2011;7:1802-1806. French.

46. Gotto J, Rapaport MH. Treatment options in treatment-resistant depression. Prim Psychiatry. 2005;12:42-50.

47. Nemeroff CB. Augmentation strategies in patients with refractory depression. Depress Anxiety. 1996-1997;4:169-181.

48. Joffe RT, Levitt AJ. Antidepressant failure: augmentation or substitution? J Psychiatry Neurosci. 1995;20:7-9.

49. Orrell M, Collins E, Shergill S, Katona C. Management of depression in the elderly by general practitioners: I. Use of antidepressants. Fam Pract. 1995;12:5-11.

50. Nierenberg AA, Papakostas GI, Petersen T, et al. Nortriptyline for treatment-resistant depression. J Clin Psychiatry. 2003;64:35-39.

51. Thase ME, Blomgren SL, Barkett MA, et al. Fluoxetine treatment of patients with major depressive disorder who failed to initial treatment with sertraline. J Clin Psychiatry. 1997;58:16-21.

52. Brown WA, Harrison W. Are patients who are intolerant to one SSRI intolerant to another? Psychopharmacol Bull. 1992;28:253-256.

53. Zarate CA, Kando JC, Tohen M, Weiss MK, Cole JO. Does intolerance or lack of response with fluoxetine predict the same will happen with sertraline? J Clin Psychiatry. 1996;57:67-71.

54. Joffe RT, Levitt AJ, Sokolov ST, et al. Response to an open trial of a second SSRI in major depression. J Clin Psychiatry. 1996;57:114-115.

55. Peselow ED, Philippi AM, Goodnick P, et al. The short- and long-term efficacy of paroxetine HC: B. data from a double blind cross-over study and from a year long term trial vs imipramine and placebo. Psychopharmacol Bull. 1989;25:272-276.

56. Thase ME, Rush AJ, Cornstein SG, et al. Double blind switch of imipramine or sertraline treatment of antidepressant resistant chronic depression. Arch Gen Psychiatry. 2002;59:232-239.

57. Nierenberg AA, Feighner JP, Rudolph R, et al. Venlafaxine for treatment resistant unipolar depression. J Clin Psychopharmacol. 1994;14:419-423.

58. De Montigny C, Silverstone PH, Debonnel G, et al. Venlafaxine for treatment resistant depression. A Canadian, multicenter open label trial. J Clin Psychopharmacol. 1999;19:401-406.

59. Kaplan EM. Efficacy of venlafaxine in patients with major depressive disorders who have unsustained or no response to selective serotonin reuptake inhibitors: an open-label, uncontrolled study. Clin Ther. 2002;24:1194-2000.

60. Poirer ME, Boyer P. Venlafaxine and paroxetine in treatment resistant depression: double-blind randomized comparison. Br J Psychiatry. 1999;175:12-16.
61. McGrath PJ, Fava M, Stewart JW, et al. Bupropion in SSRI-resistant depression. Presented at the 39th annual meeting of the American College of Neuropsychopharmacology, December 10-14, 2000, San Juan, Puerto Rico.

62. Fava M, Dunner DL, Griest JH, et al. Efficacy and safety of mirtazapine in major depressive disorder patients after SSRI treatment failure: an open label trial. J Clin Psychiatry. 2001;62:413-420.

63. Thase ME, Kremer C, Rodridgues EH, et al. Mirtazapine versus sertraline in after SSRI nonresponse. Presented at the 39th annual meeting of the American College of Neuropsychopharmacology, December 10-14, 2000, San Juan, Puerto Rico.

64. Rapaport MH, Gharabawi GM, Canuso CM, et al. Effects of risperidone augmentation in patients with treatment-resistant depression: results of open-label treatment followed by double-blind continuation. Neuropsychopharmacology. 2006;31:2505-2513.

65. Lenox-Smith AJ, Jiang Q. Venlafaxine extended release versus citalopram in patients with depression unresponsive to a selective serotonin reuptake inhibitor. Int Clin Psychopharmacol. 2008;23:113-119.

66. Souery D, Serretti A, Calati R, et al. Citalopram versus desipramine in treatment resistant depression: effect of continuation or switching strategies: a randomized open study. World J Biol Psychiatry. 2011;12:364-375

67. Rosso G, Rigardetto S, Bogetto F, Maina G. A randomized, singleblind, comparison of duloxetine with bupropion in the treatment of SSRI-resistant major depression. J Affect Disord. 2012;136:172-176.

68. Souery D, Serretti A, Calati R, et al. Switching antidepressant class does not improve response or remission in treatment-resistant depression. J Clin Psychopharmacol. 2011;31:512-516.

69. Nelson JC. Managing treatment-resistant major depression. J Clin Psychiatry. 2003;64 Suppl 1:5-12.

70. Sternbach H. The serotonin syndrome. Am J Psychiatry. 1991; 148:705-713

71. Fava M. Augmentation and combination strategies for complicated depression. J Clin Psychiatry. 2009;70:e40.

72. Boyce P, Judd F. The place for the tricyclic antidepressants in the treatment of depression. Aust N Z J Psychiatry. 1999;33:323-327.

73. Shelton RC. The use of antidepressants in novel combination therapies. J Clin Psychiatry. 2003;64:14-18.

74. Thase ME, Mallinger AG, McKnight D, Himmelhoch JM. Treatment of imipramine-resistant recurrent depression, IV: a double-blind crossover study of tranylcypromine for anergic bipolar depression. $\mathrm{Am} \mathrm{J}$ Psychiatry. 1992;149:195-198.

75. Martín-López LM, Rojo JE, Gibert K, et al. The strategy of combining antidepressants in the treatment of major depression: clinical experience in Spanish outpatients. Depress Res Treat. 2011;2011:140194.

76. Hannan N, Hamzah Z, Akinpeloye HO, Meagher D. Venlafaxinemirtazapine combination in the treatment of persistent depressive illness. J Psychopharmacol. 2007;21:161-164.

77. Malhi GS, Ng F, Berk M. Dual-dual action? Combining venlafaxine and mirtazapine in the treatment of depression. Aust N ZJ Psychiatry. 2008;42:346-349.

78. Triezenberg D, Vachon D, Helmen J, Schneider D. Clinical inquiries: how should you manage a depressed patient unresponsive to an SSRI? J Fam Pract. 2006;55:1081-1087.

79. Nelson JC, Mazure CM, Bowers MB Jr, Jatlow PI. A preliminary, open study of the combination of fluoxetine and desipramine for rapid treatment of major depression. Arch Gen Psychiatry. 1991;48:303-307.

80. de Montigny C. Lithium addition in treatment-resistant depression. Int Clin Psychopharmacol. 1994;9:31-35.

81. Philip NS, Carpenter LL, Tyrka AR, Price LH. Pharmacologic approaches to treatment resistant depression: a re-examination for the modern era. Expert Opin Pharmacother. 2010;11:709-722.

82. Nemeroff CB. Use of atypical antipsychotics in refractory depression and anxiety. J Clin Psychiatry. 2005;66 Suppl 8:13-21.

83. Philip NS, Carpenter LL, Tyrka AR, Price LH. Augmentation of antidepressants with atypical antipsychotics: a review of the current literature. J Psychiatr Pract. 2008;14:34-44. 
84. Sajatovic M, DiGiovanni S, Fuller M, et al. Nefazodone therapy in patients with treatment-resistant or treatment-intolerant depression and high psychiatric comorbidity. Clin Ther. 1999;21: 733-740.

85. Papakostas GI, Petersen TJ, Nierenberg AA, et al. Ziprasidone augmentation of selective serotonin reuptake inhibitors (SSRIs) for SSRI-resistant major depressive disorder. J Clin Psychiatry. 2004;65:217-221.

86. Parker G, Malhi G. Are atypical antipsychotic drugs also atypical antidepressants? Aust N Z J Psychiatry. 2001;35:631-638.

87. Bobo WV, Shelton RC. Efficacy, safety and tolerability of Symbyax for acute-phase management of treatment-resistant depression. Expert Rev Neurother. 2010;10:651-670.

88. Preskorn SH. Treatment options for the patient who does not respond well to initial antidepressant therapy. J Psychiatr Pract 2009;5:202-210.

89. Fabrazzo M, Perris F, Monteleone P, Esposito G, Catapano F, Maj M. Aripiprazole augmentation strategy in clomipramine-resistant depressive patients: an open preliminary study. Eur Neuropsychopharmacol. 2012;22:132-136.

90. Boku S, Inoue T, Honma H, Matsubara S, Nakagawa S, Koyama T. Olanzapine augmentation of milnacipran for stage 2 treatment-resistant major depression: an open study. Hum Psychopharmacol. June 3, 2011. [Epub ahead of print.]

91. Joffe RT, Singer W. A comparison of triiodothryonine and thyroxine in the potentiation of tricyclic antidepressants. Psychiatry Res. 1990;32:241-245.

92. Bridges PK, Hodgkiss AD, Malizia AL. Practical management of treatment-resistant affective disorders. Br J Hosp Med. 1995;54: 501-506.

93. Joffe RT, Singer W, Levitt AJ, MacDonald C. A placebo-controlled comparison of lithium and triiodothyronine augmentation of tricyclic antidepressants in unipolar refractory depression. Arch Gen Psychiatry. 1993;50:387-393.

94. Artigas F, Romero L, Perez V, Alvarez E. Augmentation of antidepressant effects with $5 \mathrm{HT}_{1 \mathrm{~A}}$ antagonists. Eur Neuropsychopharmacol. 1996;6 Suppl 3:16.

95. Hansen RA, Dusetzina SB, Ellis AR, Stürmer T, Farley JF, Gaynes BN. Risk of adverse events in treatment-resistant depression: propensityscore-matched comparison of antidepressant augment and switch strategies. Gen Hosp Psychiatry. 2012;34:192-200.

96. Fang Y, Yuan C, Xu Y, et al; OPERATION Study Team. A pilot study of the efficacy and safety of paroxetine augmented with risperidone, valproate, buspirone, trazodone, or thyroid hormone in adult Chinese patients with treatment-resistant major depression. J Clin Psychopharmacol. 2011;31:638-642.

97. Barbee JG, Thompson TR, Jamhour NJ, et al. A double-blind placebocontrolled trial of lamotrigine as an antidepressant augmentation agent in treatment-refractory unipolar depression. J Clin Psychiatry. 2011;72:1405-1412.

98. Mowla A, Kardeh E. Topiramate augmentation in patients with resistant major depressive disorder: a double-blind placebocontrolled clinical trial. Prog Neuropsychopharmacol Biol Psychiatry. 2011;35:970-973.

99. Anderson IM, Sarsfield A, Haddad PM. Efficacy, safety and tolerability of quetiapine augmentation in treatment resistant depression: an openlabel, pilot study. J Affect Disord. 2009;117:116-119.

100. Thase ME, Friedman ES, Biggs MM, et al. Cognitive therapy versus medication in augmentation and switch strategies as second-step treatments: a STAR*D report. Am J Psychiatry. 2007;164:739-752.

101. Sharma V, Mazmanian D, Persad E, Kueneman K. A comparison of comorbid patterns in treatment-resistant unipolar and bipolar depression. Can J Psychiatry. 1995;40:270-274.

102. Gruber AJ, Hudson JI, Pope HG Jr. The management of treatmentresistant depression in disorders on the interface of psychiatry and medicine. Fibromyalgia, chronic fatigue syndrome, migraine, irritable bowel syndrome, atypical facial pain, and premenstrual dysphoric disorder. Psychiatr Clin North Am. 1996;19:351-369.
103. Jann MW, Slade JH. Antidepressant agents for the treatment of chronic pain and depression. Pharmacotherapy. 2007;27:1571-1587.

104. Franco-Bronson K. The management of treatment-resistant depression in the medically ill. Psychiatr Clin North Am. 1996;19:329-350.

105. Fink M. Convulsive therapy: a review of the first 55 years. J Affect Disord. 2001;63:1-15.

106. Khalid N, Atkins M, Tredget J, Giles M, Champney-Smith K, Kirov G. The effectiveness of electroconvulsive therapy in treatment-resistant depression: a naturalistic study. J ECT. 2008;24:141-145.

107. Sackheim HA, Prudic J, Devanand DP, Decina P, Kerr B, Malitz S. The impact of medication resistance and continuation pharmacotherapy on relapse following response to electroconvulsive therapy in major depression. J Clin Psychopharmacol. 1990;10:96-104.

108. Perugi G, Medda P, Zanello S, Toni C, Cassano GB. Episode length and mixed features as predictors of ECT nonresponse in patients with medication-resistant major depression. Brain Stimul. 2012;5:18-24.

109. Ghaziuddin N, Dumas S, Hodges E. Use of continuation or maintenance electroconvulsive therapy in adolescents with severe treatmentresistant depression. JECT. 2011;27:168-174.

110. Torres CV, Lozano AM. Deep brain stimulation in the treatment of therapy-refractory depression. Rev Neurol. 2008;47:477-482.

111. Kennedy SH, Giacobbe P. Treatment resistant depression advances in somatic therapies. Ann Clin Psychiatry. 2007;19: 279-287

112. Hoy KE, Fitzgerald PB. Magnetic seizure therapy for treatmentresistant depression. Expert Rev Med Devices. 2011;8:723-732.

113. Jhanwar VG, Bishnoi RJ, Jhanwar MR. Utility of repetitive transcranial stimulation as an augmenting treatment method in treatment-resistant depression. Indian J Psychol Med. 2011;33:92-96.

114. Blumberger DM, Mulsant BH, Fitzgerald PB, et al. A randomized double-blind sham-controlled comparison of unilateral and bilateral repetitive transcranial magnetic stimulation for treatment-resistant major depression. World J Biol Psychiatry. July 8, 2011. [Epub ahead of print.]

115. Dell'osso B, Camuri G, Castellano F, et al. Meta-review of metanalytic studies with repetitive transcranial magnetic stimulation (rTMS) for the treatment of major depression. Clin Pract Epidemiol Ment Health. 2011;7:167-177.

116. Palm U, Schiller C, Fintescu Z, et al. Transcranial direct current stimulation in treatment resistant depression: a randomized double-blind, placebo-controlled study. Brain Stimul. September 7, 2011. [Epub ahead of print.]

117. Warnell RL, Elahi N. Introduction of vagus nerve stimulation into a maintenance electroconvulsive therapy regimen: a case study and cost analysis. JECT. 2007;23:114-119.

118. Sackeim HA, Rush AJ, George MS, et al. Vagus nerve stimulation (VNS) for treatment-resistant depression: efficacy, side effects, and predictors of outcome. Neuropsychopharmacology. 2001;25: 713-728

119. Lozano AM, Giacobbe P, Hamani C, et al. A multicenter pilot study of subcallosal cingulate area deep brain stimulation for treatment-resistant depression. J Neurosurg. 2012;116:315-322.

120. Kennedy SH, Giacobbe P, Rizvi SJ, et al. Deep brain stimulation for treatment-resistant depression: follow-up after 3 to 6 years. Am J Psychiatry. 2011;168:502-510.

121. Puri BK, Counsell SJ, Hamilton G, Richardson AJ, Horrobin DF. Eicosapentaenoic acid in treatment-resistant depression associated with symptom remission, structural brain changes and reduced neuronal phospholipid turnover. Int J Clin Pract. 2001;55: 560-563.

122. Podawiltz A, Culpepper L. Treatment-resistant depression in Hispanic patients. J Clin Psychiatry. 2010;71(6):e12.

123. Nemeroff CB. Improving antidepressant adherence. J Clin Psychiatry. 2003;64 Suppl 18:25-30.

124. Mota-Pereira J, Carvalho S, Silverio J, et al. Moderate physical exercise and quality of life in patients with treatment-resistant major depressive disorder. J Psychiatr Res. 2011;45:1657-1659. 
125. Brent D, Emslie J, Clark G, et al. Switching to another SSRI or to venlafaxine with or without cognitive behavioral therapy for adolescents with SSRI-resistant depression: the TORDIA randomized controlled trial. JAMA. 2008;299:901-913.

126. Hetrick SE, Cox GR, Merry SN. Treatment-resistant depression in adolescents: is the addition of cognitive behavioral therapy of benefit? Psychol Res Behav Manag. 2011;4:97-112.

127. Shamseddeen W, Clarke G, Wagner KD, et al. Treatment-resistant depressed youth show a higher response rate if treatment ends during summer school break. J Am Acad Child Adolesc Psychiatry. 2011;50:1140-1148.

128. Trivedi RB, Nieuwsma JA, Williams JW Jr. Examination of the utility of psychotherapy for patients with treatment resistant depression: a systematic review. J Gen Intern Med. 2011;26:643-650.

129. Vitiello B, Emslie G, Clarke G, et al. Long-term outcome of adolescent depression initially resistant to selective serotonin reuptake inhibitor treatment: a follow-up study of the TORDIA sample. J Clin Psychiatry. 2011;72:388-396

130. Sanacora G, Zarate CA, Krystal JH, Manji HK. Targeting the glutamatergic system to develop novel, improved therapeutics for mood disorders. Nat Rev Drug Discov. 2008;7:426-437.

131. Murrough JW, Charney DS. Lifting the mood with ketamine. Nat Med. 2010;16:1384-1385.

132. Ibrahim L, Diazgranados N, Luckenbaugh DA, et al. Rapid decrease in depressive symptoms with an N-methyl-d-aspartate antagonist in ECT-resistant major depression. Prog Neuropsychopharmacol Biol Psychiatry. 2011;35:1155-1159.

133. Witkin JM, Li X. New approaches to the pharmacological management of major depressive disorder. Adv Pharmacol. 2009;57:347-379.

134. Liang Y, Richelson E. Triple reuptake inhibitors: next-generation antidepressants. Prim Psychiatry. 2008;15:50-56.
135. Marks DM, Pae C, Patkar AA. Triple reuptake inhibitors: a premise and a promise. Psychiatry Investig. 2008;5:142-147.

136. Trivedi MH. Treatment-resistant depression: new therapies on the horizon. Ann Clin Psychiatry. 2003;15:59-70.

137. Loftis JM. Sertoli cell therapy: a novel possible treatment strategy for treatment-resistant major depressive disorder. Med Hypotheses. 2011;77:35-42.

138. Furey ML, Drevets WC. Antidepressant efficacy of the antimuscarinic drug scopolamine: a randomized, placebo-controlled clinical trial. Arch Gen Psychiatry. 2006;63:1121-1129.

139. George TP, Sacco KA, Vessicchio JC, Weinberger AH, Shytle RD. Nicotinic antagonist augmentation of selective serotonin reuptake inhibitor-refractory major depressive disorder: a preliminary study. J Clin Psychopharmacol. 2008;28:340-344.

140. Birkenhäger TK, van den Broek WW, Moleman P, Bruijn JA. Outcome of a 4-step treatment algorithm for depressed inpatients. J Clin Psychiatry. 2006;67:1266-1271.

141. Connolly KR, Thase ME. If at first you don't succeed: a review of the evidence for antidepressant augmentation, combination and switching strategies. Drugs. 2011;71:43-64.

142. Wan DD, Kundhur D, Solomons K, Yatham LN, Lam RW. Mirtazapine for treatment-resistant depression: a preliminary report. J Psychiatry Neurosci. 2003;28:55-59.

143. Stotz G, Woggon B, Angst J. Psychostimulants in the therapy of treatment-resistant depression. Review of the literature and findings from a retrospective study in 65 depressed patients. Dialogues Clin Neurosci. 1999;1:165-174.

144. Eisendrath S, Chartier M, McLane M. Adapting mindfulness-based cognitive therapy for treatment-resistant depression: a clinical case study. Cogn Behav Pract. 2011;18:362-370.
Patient Preference and Adherence

\section{Publish your work in this journal}

Patient Preference and Adherence is an international, peer-reviewed, open access journal focusing on the growing importance of patient preference and adherence throughout the therapeutic continuum. Patient satisfaction, acceptability, quality of life, compliance, persistence and their role in developing new therapeutic modalities and compounds to

\section{Dovepress}

optimize clinical outcomes for existing disease states are major areas of interest. This journal has been accepted for indexing on PubMed Central. The manuscript management system is completely online and includes a very quick and fair peer-review system. Visit http://www.dovepress.com/ testimonials.php to read real quotes from published authors. 